\title{
Diagnostic analysis of a regional heavy snowfall event over the Tibetan Plateau using NCEP reanalysis data and WRF
}

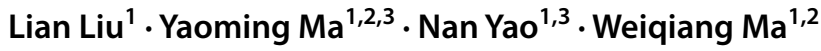

Received: 12 June 2020 / Accepted: 19 December 2020 / Published online: 7 January 2021

(c) The Author(s) 2021

\begin{abstract}
Snowstorms frequently occur in spring over the heterogeneous underlying surface of the Tibetan Plateau, causing both economic and societal damage. What the intensity of factors triggering snowstorms remains poorly understood. This study quantitatively diagnoses water vapor, the thermodynamic and dynamic conditions of a large-scale heavy snowfall event over the Tibetan Plateau using reanalysis data. Here we show, a cold vortex, the Southern Branch Trough and a meridional shear line are favorable synoptic systems. The snowfall is characterized by low-layer $\left(-8.3 \times 10^{-7} \mathrm{~g} \mathrm{~s}^{-1} \mathrm{hPa}^{-1} \mathrm{~cm}^{-2}\right)$ and whole-layer $\left(-4.5 \times 10^{-4} \mathrm{~g} \mathrm{~s}^{-1} \mathrm{~cm}^{-2}\right)$ moisture convergence, low-level atmospheric convergence and high-level divergence $\left( \pm 3 \times 10^{-4}\right.$ $\left.\mathrm{s}^{-1}\right)$, low-level positive vorticity $\left(4.8 \times 10^{-4} \mathrm{~s}^{-1}\right)$ and strong vertical velocity $\left(-4 \mathrm{~Pa} \mathrm{~s}^{-1}\right)$. Although the convectively-stable stratification acted to suppress snowfall, the abundant water vapor and strong orographic uplift of Himalayas and the downhill wind speed convergence overcome this to trigger the heavy snowfall event witnessed in March 2017. These diagnostic results are well consistent with those from WRF simulation. Our study acknowledges the importance of WRF in diagnostic analysis, deepens the understanding of evolution mechanisms and provides theoretical references for accurate forecasting of such events over the Tibetan Plateau. It would aid the development of effective strategies for sustainable livestock, and the mitigation and prevention of snow disasters in this region.
\end{abstract}

Keywords Tibetan Plateau $\cdot$ Snowfall $\cdot$ Water vapor $\cdot$ Dynamic mechanism $\cdot$ WRF

\section{Introduction}

Snow plays an important role in the water cycle, causing large variations in snow water storage and subsequent meltwater release (Liu and Qian 2005). Snow also provides a material basis for the growth of mountain glaciers. Known as the Asian water tower, the Tibetan Plateau contains the headwaters of many large rivers in Asia, supplying them with snow and glacier meltwater (Immerzeel et al. 2010). These rivers are crucial to people's daily life in the downstream

Yaoming Ma

ymma@itpcas.ac.cn

1 Key Laboratory of Tibetan Environment Changes and Land Surface Processes, Institute of Tibetan Plateau Research, Chinese Academy of Sciences, Beijing 100101, China

2 CAS Center for Excellence in Tibetan Plateau Earth Sciences, Chinese Academy of Sciences, Beijing 100101, China

3 University of Chinese Academy of Sciences, Beijing 100049, China areas, and questions around snow on the Tibetan Plateau are the focus of a large body of literature (Sato 2001; Zhang et al. 2004; Qin et al. 2006; Li et al. 2009; Wang et al. 2017).

As well as providing a vital water source, snow can also have a negative impact, and as a large proportion of China's pastoral communities inhabit the Tibetan Plateau, snowstorms can create large disruption (Shang et al. 2012; Qin et al. 2015). Snowstorms are the most destructive natural disasters in the region, when considering impacts on people and livestock (Liu et al. 2014; Wang et al. 2014). According to statistical results, snow-related disasters occur one to two times per year at the eastern edge of the Tibetan Plateau and the southern Himalayas, causing disastrous losses for animal husbandry (Gao and Qiu 2011). Animal husbandry in the eastern and central Tibetan Plateau is particularly vulnerable to severe snowfall (Wei et al. 2017). Heavy snowfall is a major threat to the economic development of a region, as well as to people's daily life. Therefore, it is urgent to study, in detail, the initialization and evolution of heavy snowfall on the Tibetan Plateau, in order to improve the accuracy 
of snow forecasts and mitigate the damage that occurs to animal husbandry during these events.

To improve the accuracy of predictions of heavy snowfall events and support an improved disaster service response in pastoral areas, the China Meteorological Administration (CMA) hosted the first national symposium on meteorological services for snow disasters in pastoral areas in September 1996, in the Xining Qinghai province of China. It was the first time that researchers had come together to conduct scientific analyses and in-depth discussions on the synoptic systems and influencing factors of, and prediction services for, snow disasters. Since this meeting, there has been increased interest in the spatial distribution, circulation patterns, physical element diagnoses, prediction and disaster assessment of heavy snowfall over the Tibetan Plateau. Jiang et al. (2016) found, in general, that there was comparatively high snowfall over the southern and eastern Tibetan Plateau, but due to a significant increase in air temperature over the eastern and northern Tibetan Plateau, snowfall over the northern Tibetan Plateau has significantly decreased (Lan et al. 2013). Likewise, the number of snowfall days and the snow depth over the eastern Tibetan Plateau have both decreased since the late 1990s (You et al. 2011; Zhu et al. 2015). In contrast to these observations, there has been a significant increase in heavy snowfall and the trend of snow-related disasters (Dong et al. 2001). Atmospheric teleconnections and local large-scale circulation anomalies are contributors to snow anomalies over the Tibetan Plateau (Li 2005; Lü et al. 2008; Yuan et al. 2009, 2012; Mao 2010; You et al. 2011; Lan et al. 2013; Jiang et al. 2019).

Heavy snowfall over the Tibetan Plateau predominantly occurs in the transition seasons for winter and summer general circulation (Zou and Cao 1989), when atmospheric circulation patterns are considered to be more important (Deng et al. 2017). It is understood that the general circulation and depression systems are the large-scale influencing factors of snowfall over the Tibetan Plateau (Zou and Cao 1991). The synoptic circulation of snowfall over the Tibetan Plateau has been classified by many researchers. Low vortex shear, low-pressure troughs, low latitude depressions and middle latitude low-pressure vortices have been identified as synoptic-scale systems that lead to heavy snowfall events, with the Southern Branch Trough playing a particularly important role (Zou and Cao 1989; Liang et al. 2002; Ueno 2005; Lin et al. 2014). Bao and You (2019) investigated the linkages between the westerly jet streams and snow depth on the Tibetan Plateau and found that the intensity of the variation and meridional shifts of the westerly jets greatly influenced snow depth by triggering cold low-pressure vortices, and the ascending motion of secondary circulations.

In order to explore the initialization and evolution mechanisms of local heavy snowfall over the Tibetan Plateau, a lot of research has been focused on water vapor and the thermodynamic and dynamic conditions (Zhang et al. 2004; Dong et al. 2018); cold and warm airflow convergence, low-level strong cyclonic vorticity, high-level divergence concurrent with low-level convergence, water vapor transportation and upward motion each play significant roles (Zou and Cao 1991; Shaman and Tziperman 2005; Dong et al. 2018; Wang et al. 2018). Additional to these atmospheric considerations, local topography strongly influences topographic snowfall (Zou and Cao 1991), and further study has been suggested on the energy and water vapor exchanges caused by complex terrain uplift (Fu et al. 2020). These dynamic and thermodynamic factors need to be considered in concert to diagnose and analyze the evolution of heavy snowfall events; this understanding is foundational to the prediction and early warning of any local heavy snowfall event over the Tibetan Plateau.

There is a strong body of literature that offers data on local heavy snowfall events over the Tibetan Plateau, however, there is a dearth of information available about the comprehensive diagnose of the initialization and evolution mechanisms of regional snowfall events. Based on previous studies, this paper uses snow-related observations from CMA stations, meteorological data from the Meteorological Information Comprehensive Analysis and Process System (MICAPS) and the highest resolution National Centers for Environmental Prediction (NCEP) reanalysis dataset to diagnose and analyze the synoptic circulation, jet configuration, water vapor, thermodynamic and dynamic conditions of a large-scale severe snowfall event which occurred in midMarch 2017 over a large proportion of the Tibetan Plateau. This work explores the initialization and development mechanisms of this large-scale heavy snowfall event, in order to provide a theoretical basis and scientific evidence to assist in short-term forecasting of such events, and contribute to disaster prevention and mitigation in the future.

\section{Data}

Data on snowfall amount and snow depth used in this study come from CMA ground observations. Snow depth is recorded at a 3-h interval. Precipitation is classified as snow when the air temperature is less than $0{ }^{\circ} \mathrm{C}$, and using this classification, data on accumulated daily snowfall amount is reported. Meteorological elements (air temperature, dewpoint temperature, precipitation, wind speed and direction) at the CMA's Nyalam station come from the MICAPS dataset, which is collected every $3 \mathrm{~h}$. We used these ground meteorological observations to clarify changes of the snowfall intensity and meteorological elements during the largescale heavy snowfall event. 
To analyze the circulation situation and diagnose the related elements, we used the NCEP Final Operational Global Analysis dataset. This product is produced using the Global Data Assimilation System. We chose a horizontal resolution of $0.25^{\circ}$ with a 6-h interval, which is available from the website https://rda.ucar.edu/datasets/ds083.3/. We used the geopotential height, temperature and wind field from NCEP Final Analysis dataset to analyze synoptic systems (i.e. depression, cold vortex, trough, jet stream and shear line). We also used NCEP Final Analysis dataset to diagnose water vapor (i.e. specific humidity, water vapor flux and its divergence), dynamic (i.e. divergence, vorticity and vertical velocity) and thermal (i.e. temperature advection and pseudo-equivalent potential temperature) conditions. To verify the NCEP analysis results, we conducted a numerical experiment around the Tibetan Plateau using the Weather Research and Forecasting (WRF) model version 3.7.1. WRF is a state-of-the-art mesoscale numerical weather prediction system designed not only for atmospheric research, but also for operational forecasting applications (Skamarock et al. 2008). The configuration and design of the WRF experiment in our current study was described thereinafter.

\section{Description of the severe snow event}

Spring snow anomalies on the Tibetan Plateau can be associated with summer monsoonal precipitation in East Asia (Xiao and Duan 2016). A particularly heavy spring snowfall occurred over a large proportion of the Tibetan Plateau in mid-March 2017. The intensity of this snowfall event was variable, from light snow in some areas, to heavy snow seen in the eastern, middle and southern edge of the Tibetan Plateau. This was an extreme event with ground snow depth observations never recorded before in the eastern Tibetan Plateau i.e. Minyang, and in the top 4 percentile in the eastern and southern Tibetan Plateau i.e. Nyalam and Songpan by our historical statistics of ground snow depth observations for more than 50 years.

We collected ground observations of daily precipitation on the Tibetan Plateau and the surrounding areas. The distribution of ground stations and the daily snowfall amount (including snowstorms) observed by CMA ground stations are showed in Fig. 1. It can be seen that the area of snowfall is slowly moving northeastwards. A large-scale, narrow and long snow belt appeared on March 11, covering parts of the eastern, central and southern regions of the Tibetan Plateau. This snow belt was about $2000 \mathrm{~km}$ long and $250 \mathrm{~km}$ wide. Heavy snowfall moved to the eastern Tibetan Plateau on March 12, but weakened to light snow on March 13 (Fig. 1b). From March 10 to 12, eight CMA stations in the eastern and southern edges of the Tibetan Plateau recorded severe snowstorms (Fig. 1c). The maximum daily snowfall over these days for each of the eight stations was $63.3 \mathrm{~mm}$ at Nyalam, $18.6 \mathrm{~mm}$ at Pagri, $15.8 \mathrm{~mm}$ at Cona, $15.2 \mathrm{~mm}$ at Daqaidam, $13.8 \mathrm{~mm}$ at Minyang, $13.7 \mathrm{~mm}$ at Ngawa, $10.7 \mathrm{~mm}$ at Qiongxi and $10.2 \mathrm{~mm}$ at Songpan. The severe snowfall at Nyalam station lasted for 2 days, with the accumulated snowfall reaching $114.3 \mathrm{~mm}$. According to CMA ground observations of snow depth, deep snow appeared in the southern edge of the Tibetan Plateau, with $77 \mathrm{~cm}$ at Nyalam, $47 \mathrm{~cm}$ at Pagri and $33 \mathrm{~cm}$ at Cona. The large amount, strong intensity, wide extent and thick depth of the snowfall during this event are rare in the observational record of this area.

The continuous occurrence of severe snowstorm at Nyalam station is related to its geographical location. Nyalam County is located on the south slope of the Himalayas, with an average altitude of $4300 \mathrm{~m}$, which is easily affected by steep Himalayas uplifting the southwestern warm moist airflow and as a result, leading to frequent and heavy precipitation recorded at Nyalam County. In the middle of March 2017, the average snow depth exceeded $1 \mathrm{~m}$ in Nyalam County, and the county suffered through its largest blizzard for recent 30 years. Based on the observations of meteorological elements i.e. air temperature, dew-point temperature, precipitation, wind speed and direction from Nyalam station (Fig. 2), prior to the blizzard there was a gradual decrease in air temperature and a significant increase in dew-point temperature, followed by a considerable drop in the depression of the dew-point temperature and gradual increase in humidity. During the blizzard period, both air and the depression of the dew-point temperature were consistently low; air temperature stayed around $\sim-4{ }^{\circ} \mathrm{C}$, and the depression of the dew-point temperature reached a minimum of $1.2{ }^{\circ} \mathrm{C}$ at 08:00 Beijing standard time (BST) on March 11 (Fig. 2a). Humid and cold air dominated, and southeasterly winds prevailed at Nyalam station, with wind speeds sharply increasing from 5 to $18 \mathrm{~m} \mathrm{~s}^{-1}$ (Fig. 2b). After the snowstorm, both the air and dew-point temperature rapidly decreased further, after which the depression of the dew point recovered. Simultaneously, dry, cold air dominated and the wind speed gradually decreased.

\section{The synoptic situation}

\subsection{Circulation at $500 \mathrm{hPa}$}

Favorable synoptic conditions play an important role in the occurrence of a severe snowfall (Wang et al. 2015), and the mid-latitude circulation anomalies tend to produce snowfall in the central Tibetan Plateau (Ueno 2005). In order to investigate the role of circulations on the initialization and evolution of the heavy snow event, we analyze the circulation at $500 \mathrm{hPa}$ before and after this snow event as shown 

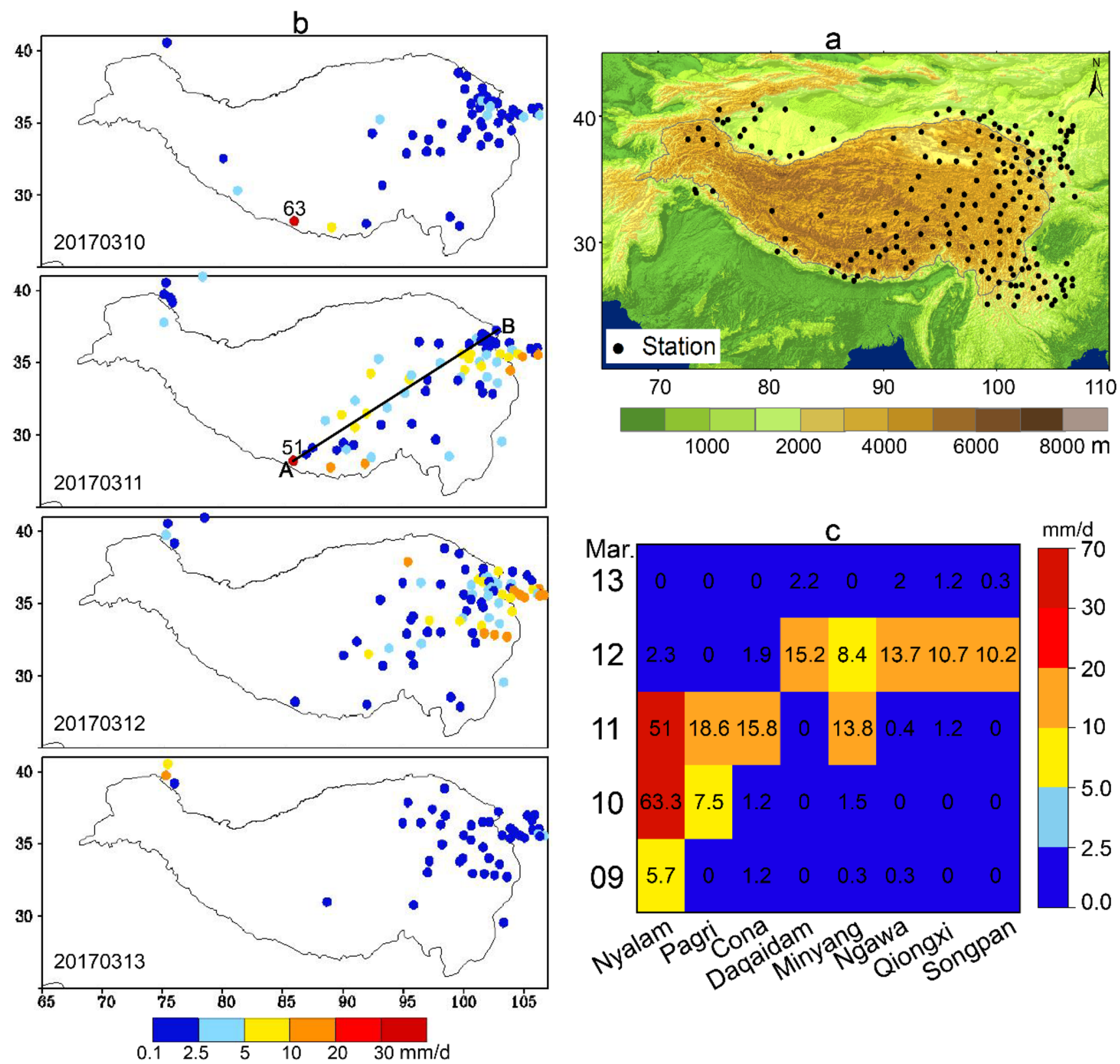

Fig. 1 Topography of a 3 arc-seconds Shuttle Radar Topography Mission (SRTM), with the distribution of the meteorological stations in black solid circles (a), the distribution of daily snowfall amount

in Fig. 3. On March 9, 2017, the Asian circulation pattern in the middle and high latitudes presented as a multi-trough and multi-ridge type, and Lake Balkhash was under the control of southwesterly flow in front of the trough (Fig. 3a). With the thermal trough lagging behind the pressure trough, a backward-tilting trough was generated around Lake Balkhash. The pressure trough nearby continued to rotate, and on March 11, developed into a tilted trough extending to the southwest (Fig. 3b). The southwesterly flow in front of the tilted trough cut off the southward movement of cold (b) and its values at stations where a snowstorm occurred (c) during the snowfall event. Points A and B are the locations of Nyalam and Wushaoling stations respectively

air, resulting in cold air piling up near the low-pressure center and forming a cold vortex above Lake Balkhash, with a center temperature less than $-32{ }^{\circ} \mathrm{C}$. In addition, the Southern Branch Trough moved eastward and deepened. A large proportion of the Tibetan Plateau was controlled by the strong southwesterly flow in front of the Southern Branch Trough, which was conducive to water vapor transportation from Bay of Bengal to the Tibetan Plateau. Under the control of a small high-pressure system, a long meridional shear line was generated in the northern edge of the Tibetan Plateau. 

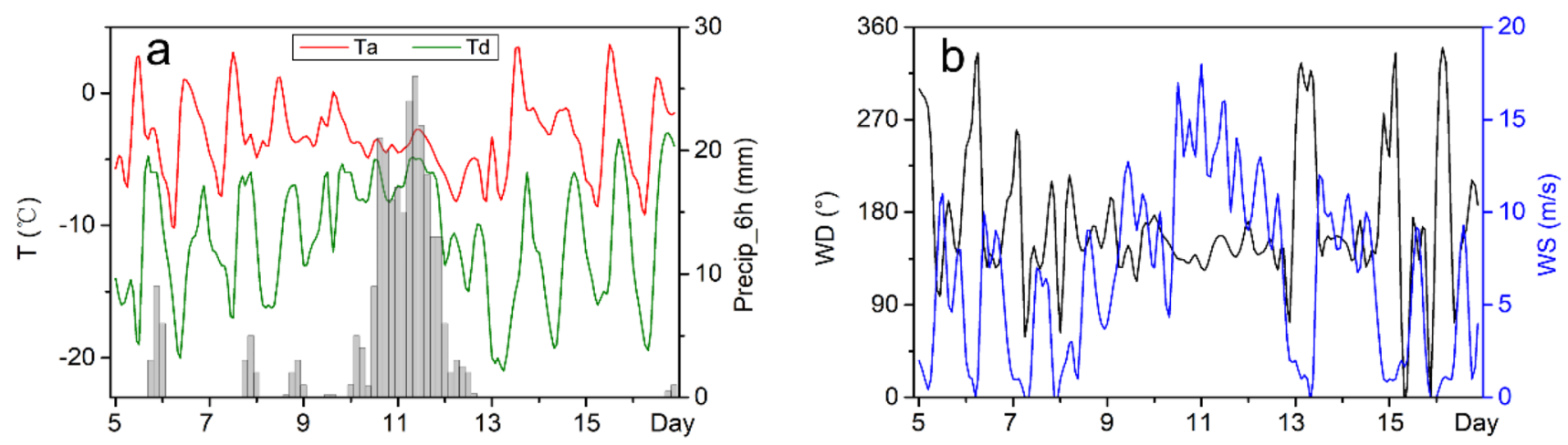

Fig. 2 Meteorological variables at Nyalam station, including air temperature (red line), dew-point temperature (green line), 6-hourly accumulated precipitation (grey column), wind speed (blue line) and wind direction (black line)
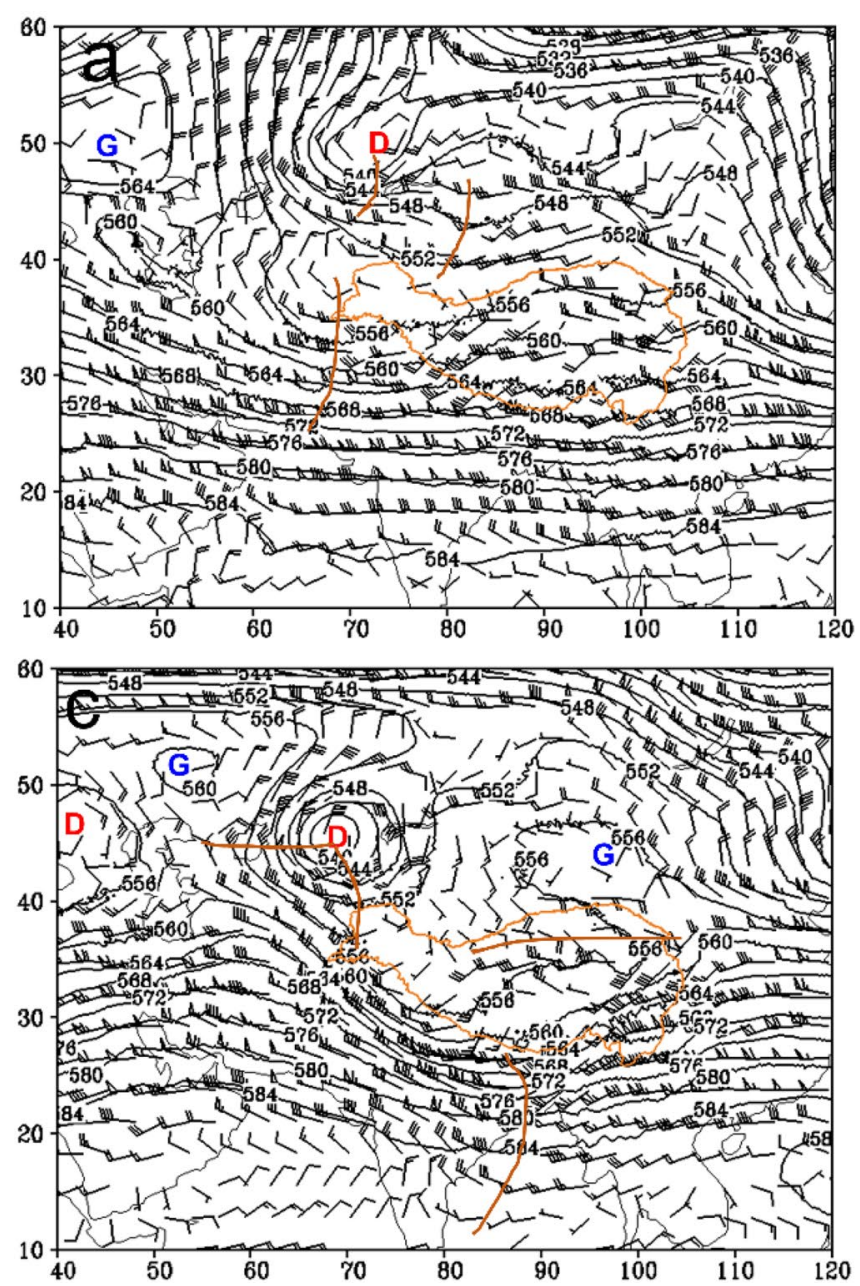

Fig. 3 Geopotential height in units of dagpm in black isoline and wind field at $500 \mathrm{hPa}$ in wind barb at 08:00 BST on March 9 (a), 11 (b), 12 (c) and 14 (d). Brown thick lines are trough lines and wind

The cold vortex stabilized above Lake Balkhash on March 12. The tilted trough extended to the northwestern border
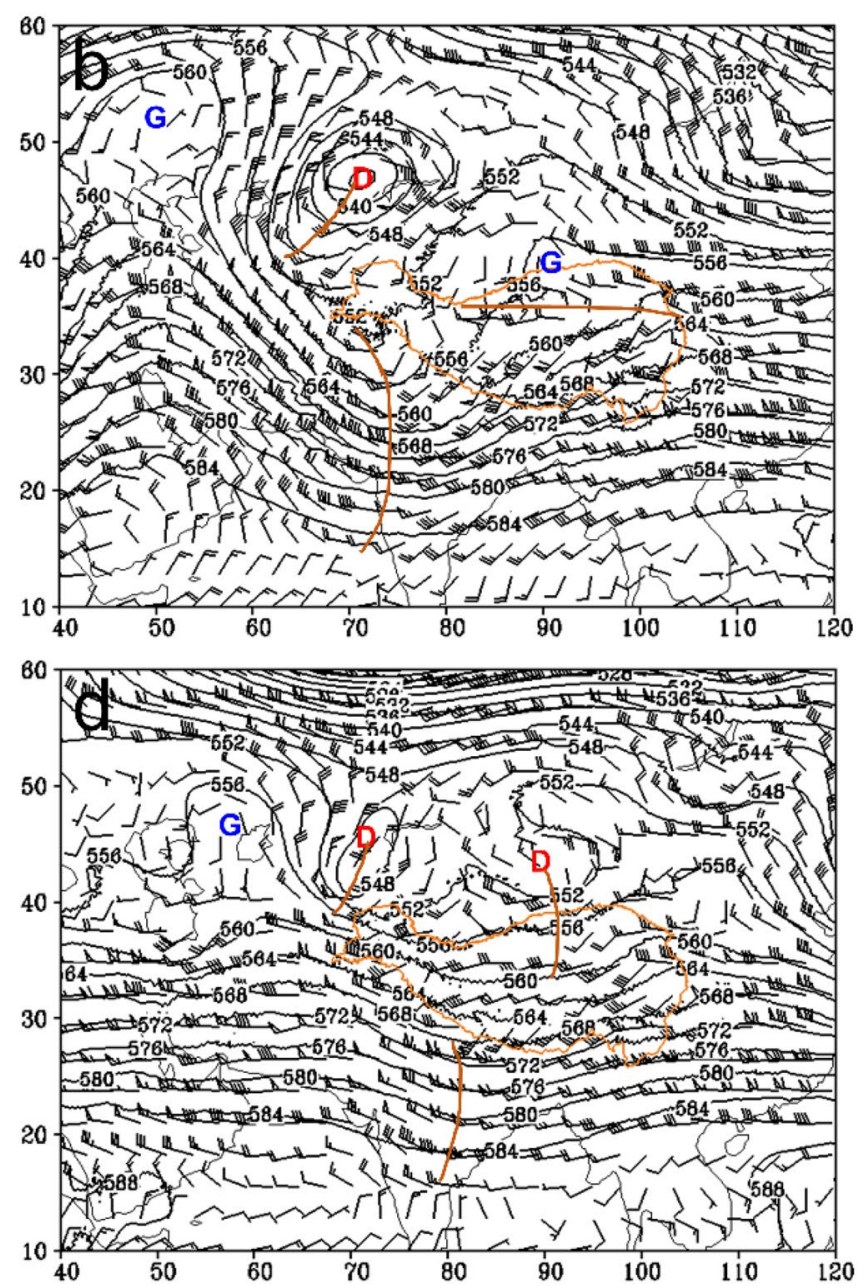

shear lines; brown thin lines are the Tibetan Plateau boundaries. D and $\mathrm{G}$ are the locations of low and high pressure centers respectively

of the Tibetan Plateau, which was conducive to the transportation of cold air to the northwest. The Southern Branch 
Trough moved eastward and gradually weakened, and split, in step-like way, when climbing up to the western border. The southern and eastern Tibetan Plateau was controlled by the strong southwesterly flow in front of the Southern Branch Trough, leading to continuous water vapor transportation from the Bay of Bengal to these regions. The eastern boundary of the meridional shear line moved northward by about two degrees of latitude, maintaining snowfall over the Tibetan Plateau and the northward expansion of snowfall over the eastern regions (Fig. 3c). Lake Balkhash cold vortex weakened with the central index value increase to 548 dagpm. The Tibetan Plateau was controlled by the westerly flow with small troughs moving eastward. The long meridional shear line in the northern Plateau disappeared, and the northern Plateau was controlled by the southward of lowpressure in the eastern Lake Balkhash (Fig. 3d).

\subsection{Upper and lower jet configuration}

During periods of the severe snowfall event, the lower southwesterly jet sat to the south of the entire Plateau, which allowed for the development of convergence and a rising of the near surface airflow. This supported the generation and strengthening of precipitation over the Plateau.

The divergence field from secondary circulations of the upper westerly jet provided a pathway for the near surface airflow to rise and, therefore, the development and evolution of the conditions for snowfall (Bao and You 2019). In order to investigate the role of upper jet on this severe snowfall event, the horizontal current and wind speed at $200 \mathrm{hPa}$ are displayed in Fig. 4. Clearly, over the period of the event, the axis of the upper jet moved eastward over the southern
Tibetan Plateau (Fig. 4). At 08:00 BST on March 11, the exit region for the upper jet was located to the southeast of the Plateau (Fig. 4a), causing divergent airflow dominating the eastern Plateau. In combination with the development and evolution of the lower jet, the eastern region was affected by the synergy of upper divergence and lower convergence, triggering strong upward movement and enhanced snowfall intensity. At 08:00 BST on March 12, The entrance region for the upper jet sat to the south of the central Himalayas, leading to the central Himalayas being characterized by a negative vorticity advection and a convergence current, and, being controlled by the sinking branch of the direct circulation brought about by the upper jet, which acted to suppress snowfall in the central Himalayas (Fig. 4b).

\section{Diagnostic analysis}

\subsection{Water vapor}

Apart from the favorable synoptic systems, an abundant supply of water vapor is also important for the occurrence and maintenance of snowfall (Dong et al. 2018). In order to analyze the water vapor condition of the whole layer, a vertical cross section of specific humidity along the narrow snow belt is displayed in Fig. 5. It is clear that the water vapor focuses on the near surface. At 20:00 BST on March 10 , the specific humidity at surface was about $1.5 \mathrm{~g} \mathrm{~kg}^{-1}$ in the southern and central Plateau, while about $3.5 \mathrm{~g} \mathrm{~kg}^{-1}$ in the lower topographic eastern Plateau (Fig. 5a); this is favorable to provide humid mass for solid precipitation in eastern region. At night on March 11, specific humidity at
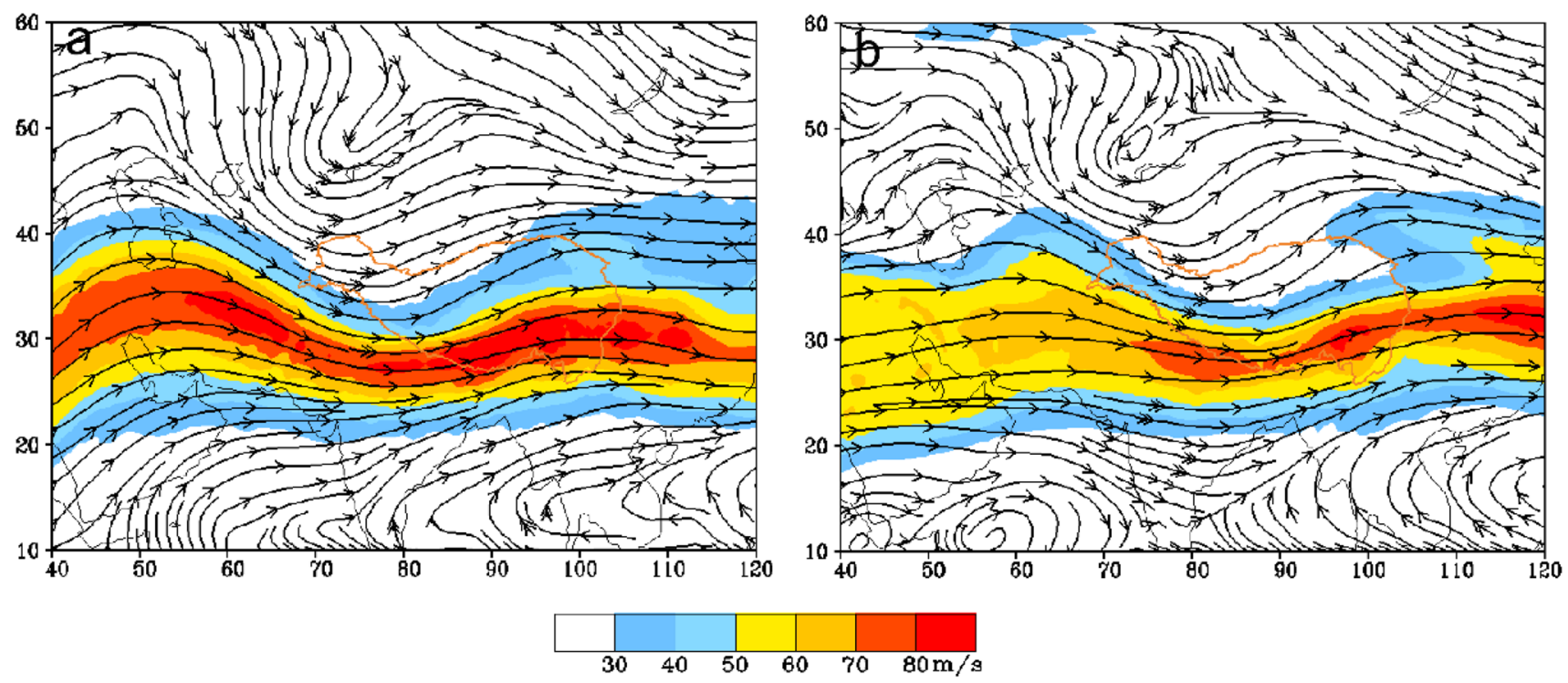

Fig. 4 Wind field in streamline and wind speed in shaded at $200 \mathrm{hPa}$ at 08:00 BST on March 11 (a) and 12 (b) 

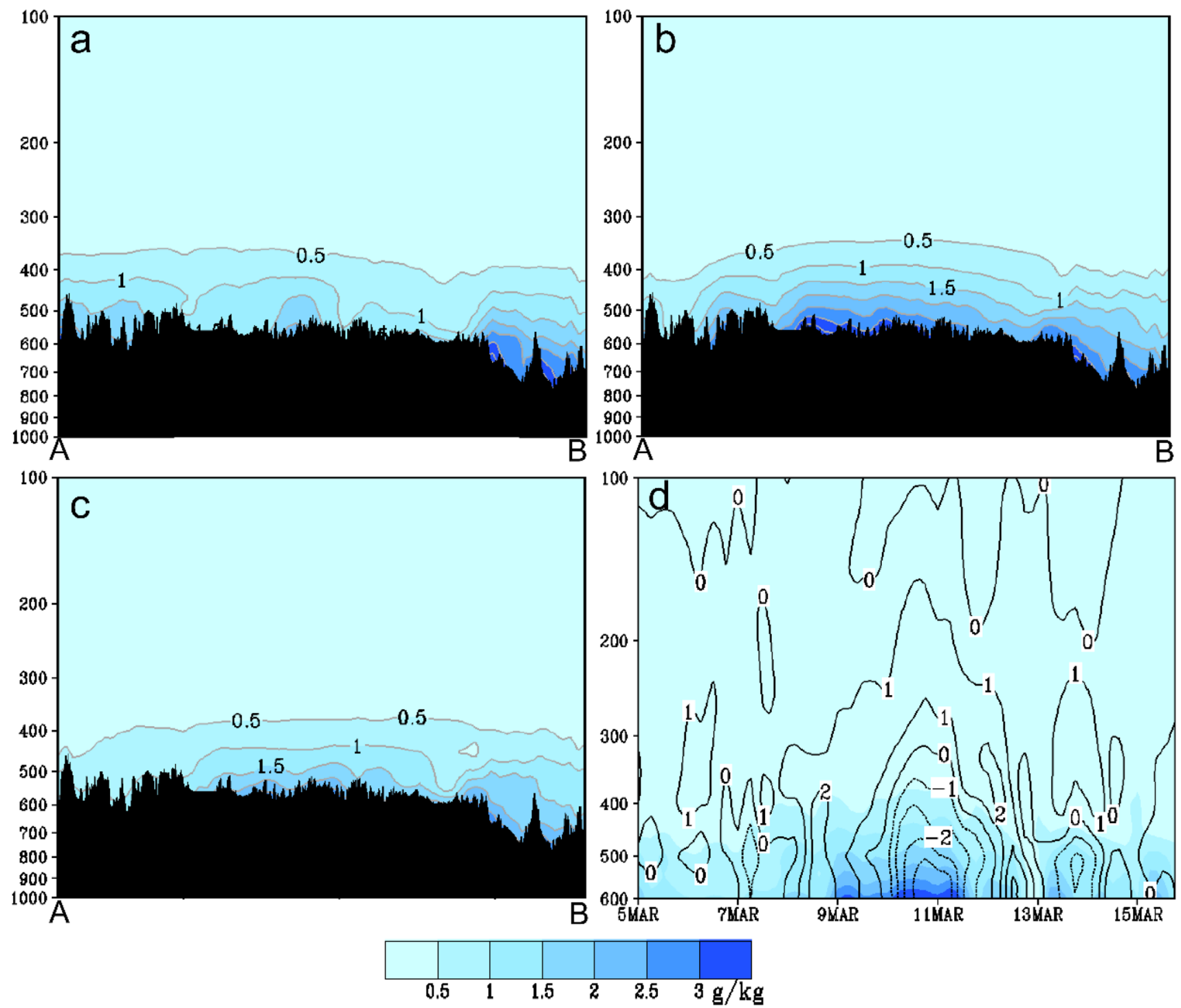

Fig. 5 Profile of specific humidity along line AB at 20:00 BST from March 10 to 12 in blue shaded and isoline at $0.5 \mathrm{~g} \mathrm{~kg}^{-1}$ interval $(\mathbf{a}-\mathbf{c})$. Black shadow is the 3 arc-seconds SRTM elevation along line AB.

surface doubled in the central region, but decreased in the southern mountain region, while kept high values in the eastern Plateau. Two-thirds of the snow belt was controlled by surface specific humidity higher than $2.5 \mathrm{~g} \mathrm{~kg}^{-1}$ with a maximum specific humidity of $3.5 \mathrm{~g} \mathrm{~kg}^{-1}$ in the central and eastern region. Remarkably, the air column along the snow belt became extremely wet and deep especially in the central region (Fig. 5b), which provides considerable water vapor condition for the formation of the large-scale snow belt over the Tibetan Plateau. However, at 20:00 BST on March 12, the air column along the snow belt appeared relatively dry and shallow with surface specific humidity less than $1 \mathrm{~g} \mathrm{~kg}^{-1}$ in the southern region and about $2 \mathrm{~g} \mathrm{~kg}^{-1}$ in the central and eastern region (Fig. 5c); such the insufficient water vapor
For a description of points A and B, see Fig. 1. The specific humidity profile is shaded and the isoline is the vertical velocity in a pressure coordinate system, with units of $\mathrm{Pa} \mathrm{s}^{-1}$ at Nyalam station (d)

suppresses the continuation of the snow belt, and is a nonignorable factor causing snowfall intensity to weaken and the narrow snow belt to disappear.

The boundary specific humidity at Nyalam station appeared to be high from March 9 to 11 , reaching $3 \mathrm{~g} \mathrm{~kg}^{-1}$. Simultaneously, the moisture column along Nyalam station appeared relatively deep. At night from March 10 to 11, this station was controlled by a thick high specific humidity layer coupled with strong upward motion. The thick wet air moved upward from the near surface to $350 \mathrm{hPa}$, and the strongest upward motion occurred in the near surface, with an upward velocity more than $4 \mathrm{~Pa} \mathrm{~s}^{-1}$ (Fig. 5d). These illustrate the favorable moisture and dynamic conditions that lead to the two-day severe snowstorm experienced at Nyalam station. 
Due to lower specific humidity on March 12, the snowfall grade at Nyalam station changed from snowstorm to light snow, corresponding to a daily snowfall of only $2.3 \mathrm{~mm}$ (Fig. 1c).

Water vapor flux determines the source and transport intensity of water vapor. Because of water vapor concentrating in the lower layer, we calculated the water vapor flux and its divergence at $500 \mathrm{hPa}$ as shown in Fig. 6 to specify water vapor source and transportation in the Tibetan Plateau. It can be seen that at 20:00 BST on March 10, water vapor in northern India was transported to the northeast with a maximum water vapor flux of $5 \mathrm{~g} \mathrm{~s}^{-1} \mathrm{hPa}^{-1} \mathrm{~cm}^{-1}$. After water vapor entered the Tibetan Plateau, an obvious water vapor flux convergence belt formed on the Plateau, with a maximum water vapor flux convergence of $-6.1 \times 10^{-7} \mathrm{~g} \mathrm{~s}^{-1}$
$\mathrm{hPa}^{-1} \mathrm{~cm}^{-2}$, providing a key condition for heavy snowfall in Nyalam. The water vapor transport was characterized by weak convergence in the eastern Tibetan Plateau, leading to the occurrence of light snowfall (Fig. 6a). At 08:00 BST on March 11, the water vapor transport channel expanded and the transport intensity increased to $10 \mathrm{~g} \mathrm{~s}^{-1} \mathrm{hPa}^{-1} \mathrm{~cm}^{-1}$. Water vapor converged at the southern border of the Plateau, resulting in heavy snowfall in the southern Himalayas, including Nyalam, and a significant increase in specific humidity. After the water vapor crossed over the high topographic Himalayas, the transport intensity weakened, but a long and narrow water vapor flux convergence belt formed from the eastern to central Plateau (Fig. 6b). Subsequently, the water vapor transport channel moved eastward to the Bay of Bengal and the transport intensity increased, while partial
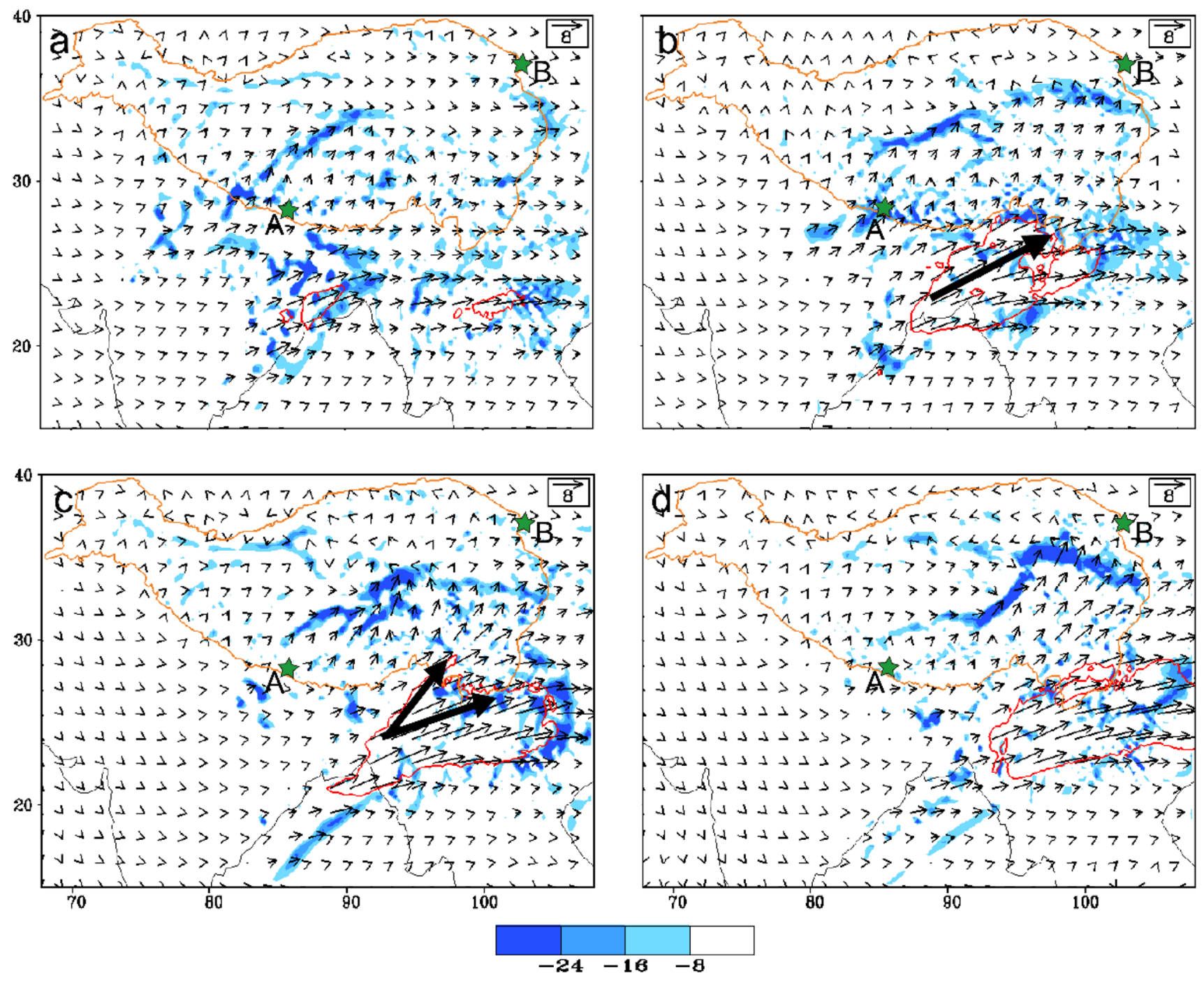

Fig. 6 The distribution of water vapor flux at $500 \mathrm{hPa}$ in units of $\mathrm{g} \mathrm{s}^{-1} \mathrm{hPa}^{-1} \mathrm{~cm}^{-1}$, and its convergence in shaded in units of $10^{-8} \mathrm{~g} \mathrm{~s}^{-1}$ $\mathrm{hPa}^{-1} \mathrm{~cm}^{-2}$, at 20:00 BST on March 10 (a), 08:00 BST (b) and 20:00 BST (c) on March 11, and 02:00 BST on March 12 (d). The thick arrow shows the water vapor transport channel. The red line is water vapor flux value of $8 \mathrm{~g} \mathrm{~s}^{-1} \mathrm{hPa}^{-1} \mathrm{~cm}^{-1}$. For a description of points $\mathrm{A}$ and $\mathrm{B}$, see Fig. 1 
water vapor entered the eastern Plateau. At night on March 11, wet air in the southern Plateau resulting from the heavy snowfall was transported northward by the southerly, and the water vapor strongly converged in the central Plateau, with a convergence intensity as high as $-7.5 \times 10^{-7} \mathrm{~g} \mathrm{~s}^{-1} \mathrm{hPa}^{-1}$ $\mathrm{cm}^{-2}$ (Fig. 6c). The water vapor convergence belt was situated close to the snow belt, an important condition for the appearance of the large-scale narrow snow belt on March 11 . At 02:00 BST on March 12, the water vapor transport channel expanded eastward, and the water vapor from the Bay of Bengal was transported to the southern and eastern Tibetan Plateau, forming an inverted V-shaped strong water vapor convergence belt in these regions, with convergence intensity increasing to $-8.3 \times 10^{-7} \mathrm{~g} \mathrm{~s}^{-1} \mathrm{hPa}^{-1} \mathrm{~cm}^{-2}$ (Fig. 6d). This provided very favorable water vapor conditions for the occurrence of heavy snowfall and even snowstorms in the central and eastern Tibetan Plateau. However, there was no obvious water vapor flux convergence around Nyalam at this time, which was a key reason why the heavy snowfall at Nyalam reduced to only a light snowfall.

Water vapor showed weak divergence above $200 \mathrm{hPa}$. The water vapor flux of the full layer was characterized by a long and narrow convergence belt over the central Tibetan Plateau, from the night of March 10 to March 11, with the convergence intensity reaching a maximum of $-3.5 \times 10^{-4}$ $\mathrm{g} \mathrm{s}^{-1} \mathrm{~cm}^{-2}$. Afterwards, the strong whole layer water vapor flux convergence occurred mainly over the eastern Plateau, where convergence intensity increased to $-4.5 \times 10^{-4} \mathrm{~g} \mathrm{~s}^{-1}$ $\mathrm{cm}^{-2}$. Taken together, these water vapor conditions lead to the enhancement of snowfall, and even the formation of snowstorms over the central and eastern Tibetan Plateau.

\subsection{Dynamic conditions}

\subsubsection{Vorticity}

Local vorticity variations affect the occurrence and development of synoptic systems. Positive vorticity advection is conducive to the enhancement of ascending motion and the development of cyclonic circulation through increases in local vorticity. On the contrary, negative vorticity advection is conducive to the development of anticyclonic circulation by the reduction of local vorticity. The profile of vertical relative vorticity along the narrow snow belt is displayed in Fig. 7. It can be seen that low-level positive and negative vorticity closely arranged along the snow belt during the period of the snowfall event (Fig. 7). Due to ascending motion and the low-level southwesterly flow, positive vorticity advection occurs in the vertical and horizontal directions along the snow belt. The denser the vorticity isolines, the larger the vorticity gradient, leading to stronger positive vorticity advection, which is very conducive to the development and enhancement of local upward movement. These are important dynamic factors for the large-scale snow belt formation and snowfall enhancement that was seen over the central and eastern Tibetan Plateau. During the heavy snowfall event, the low-level positive vorticity increased continuously. Before dawn of March 12, the maximum positive vorticity appeared in the central and eastern Plateau, with the maximum as high as $4.8 \times 10^{-4} \mathrm{~s}^{-1}$. Positive vorticity advection was very strong to the east of this maximum, shown by dense isovorticity lines (Fig. 7d).

During the severe snowfall, the positive vorticity over Nyalam spread from the lower layers to almost the entire vertical profile. With the outbreak of the snowstorm, the vorticity over Nyalam was characterized by upper negative and lower positive values (Fig. 7a), which was conducive to generating the positive vorticity advection and the enhancement of the local ascending motion and snowfall intensity. With an increase of the high-level vorticity over Nyalam (Fig. 7b-d), the vorticity difference between the high and low levels decreased significantly, causing attenuation of the positive vorticity advection and a weakening in the snowfall intensity.

\subsubsection{Vertical velocity}

Positive vorticity advection, lower wind convergence and upper wind divergence all enhance ascending motion, and strong ascending motion is closely related to heavy snowfall. The cross section of the 3-D wind vectors along the narrow snow belt as shown in Fig. 8 indicates that the ascending and descending motions on the snow belt are distributed alternately, and that the strong ascending motion (vertical velocity $<-1 \mathrm{~Pa} \mathrm{~s}^{-1}$ ) develops eastwards, with the strong ascending center generally below $400 \mathrm{hPa}$ during the heavy snowfall event. In addition, the intensity of the ascending movement over Nyalam gradually decreased over the duration of the event, and decreased considerably from the night of March 11 to March 12, with the vertical velocity dropping from -3 to $-1 \mathrm{~Pa} \mathrm{~s}^{-1}$ (Fig. 8c, d). The Nyalam surroundings were characterized by descending motion, and these conditions lead to the rapid weakening of snowfall intensity at Nyalam after the two-day snowstorm.

Overall, the intensity of the ascending motion in the snow belt was relatively weak, with the strong ascending motion only affecting a small region at 20:00 BST on March 10 when weak snowfall was present (Fig. 8a). On March 11, two-thirds of the snow belt was controlled by locally strong ascending motion with a maximum vertical velocity of $-2.3 \mathrm{~Pa} \mathrm{~s}^{-1}$ (Fig. 8b, c); this was an important condition for the formation of the large-scale snow belt over the Tibetan Plateau. At 02:00 BST on March 12, the central and eastern Plateau were controlled by strong ascending motion from the near surface to $300 \mathrm{hPa}$, with a maximum vertical velocity of $-4 \mathrm{~Pa} \mathrm{~s}^{-1}$ (Fig. 8d), which presented much stronger upward 

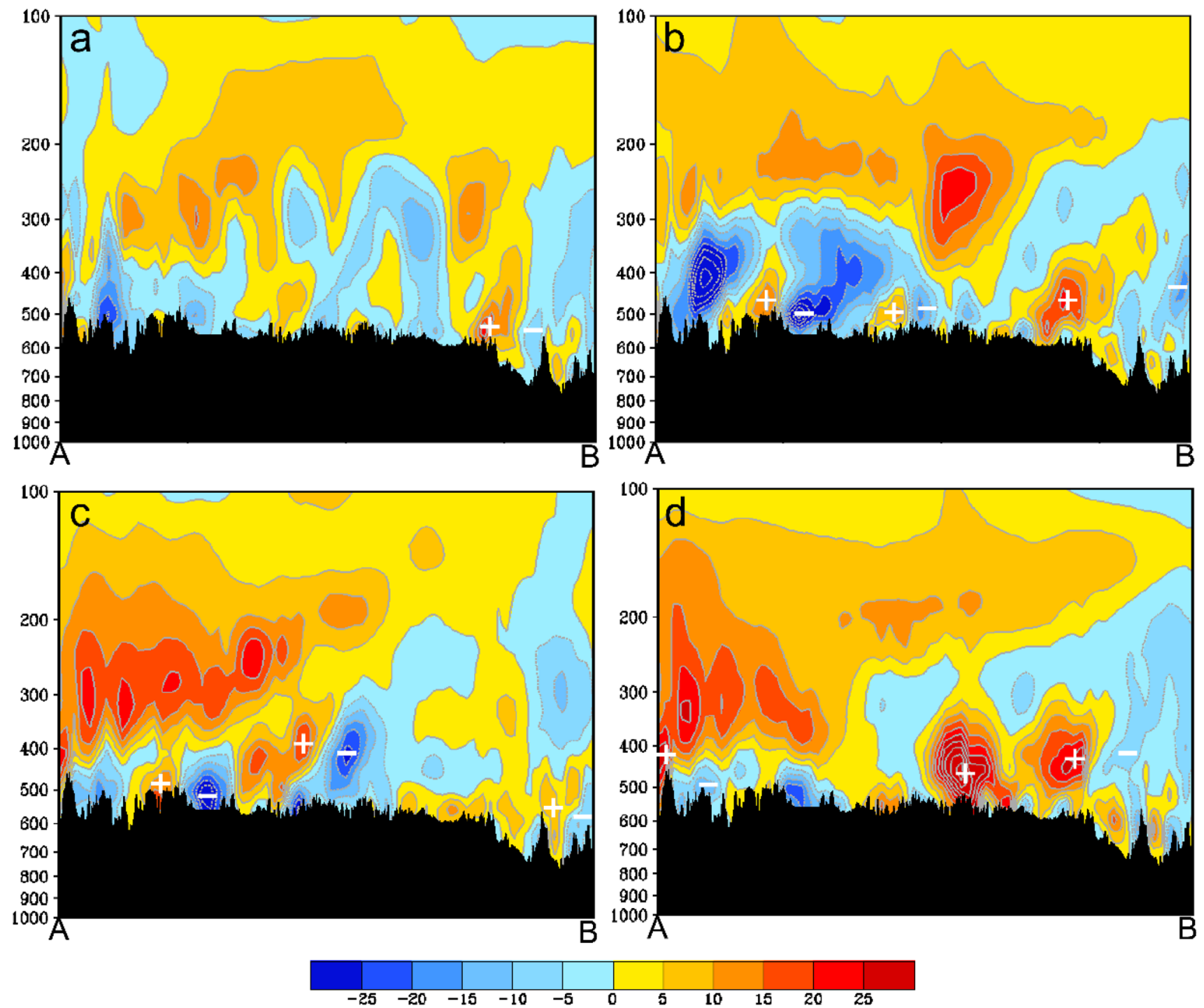

Fig. 7 Profile of vertical relative vorticity along line $A B$ at 20:00 BST on March 10 (a), 08:00 BST (b) and 20:00 BST (c) on March 11, and 02:00 BST on March 12 (d) in color shaded and isoline at
$5 \times 10^{-5} \mathrm{~s}^{-1}$ interval. For a description of points A and B, see Fig. 1. For a description of black shadow, see Fig. 5

warm advection being $2.5 \times 10^{-3} \mathrm{~K} \mathrm{~s}^{-1}$ at $250-300 \mathrm{hPa}$ above the southern Plateau. With this thermal structure, strong warm advection in the upper layer and weak cold advection in the lower layer, the lapse rate of temperature reduces and stable stratification occurs, suppressing the onset and/or development of severe snowfall events.

The change of pseudo-equivalent potential temperature with height is one of the criteria for convective stability. During the heavy snowfall event of March 2017, the pseudo-equivalent potential temperature increased with height, indicating that the atmosphere was convectively stable. Thus, it was not conducive to the occurrence of heavy snowfall. However, heavy snowfall can also take 

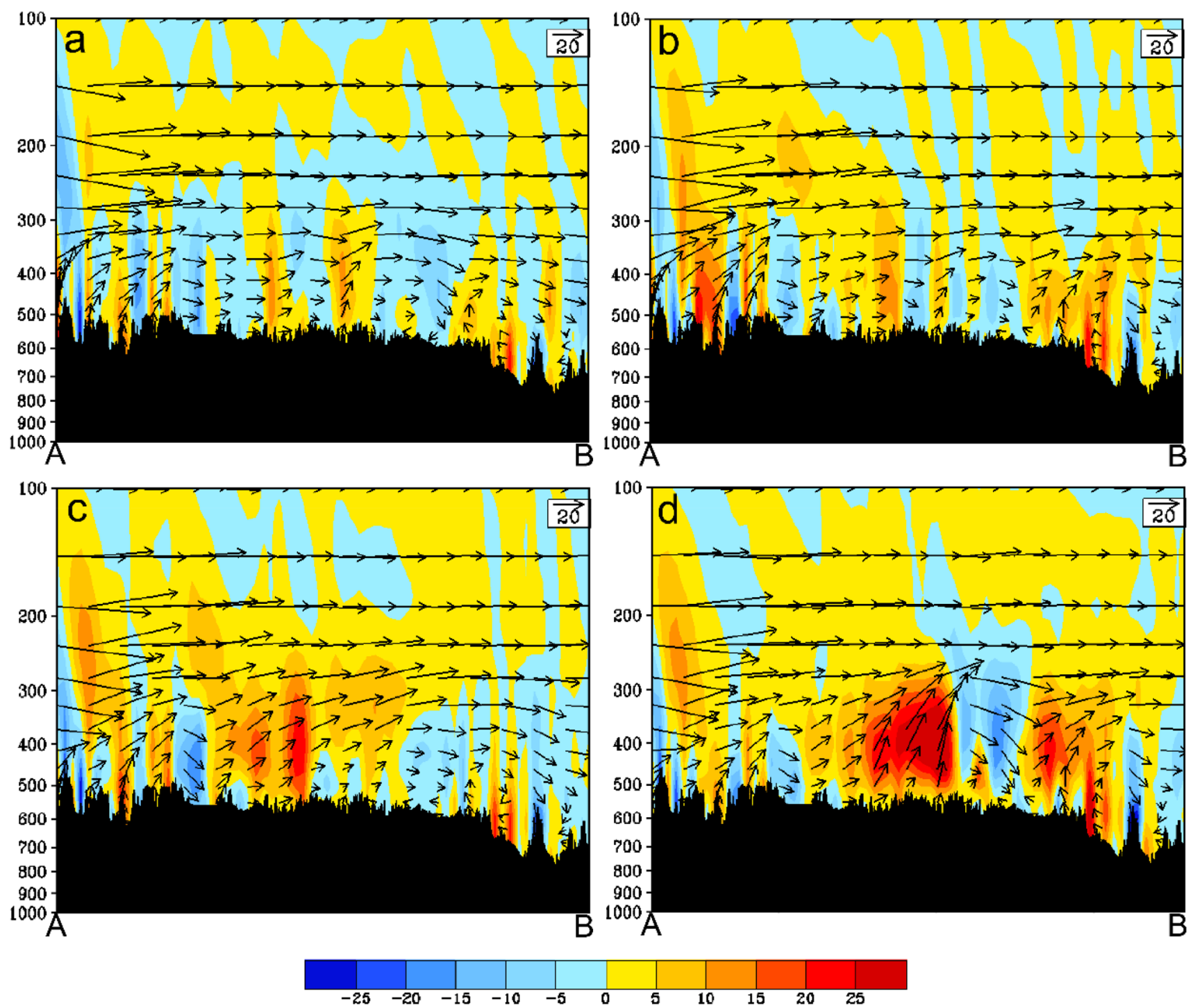

Fig. 8 Same as Fig. 7, but the profile of wind vectors as arrows in units of $\mathrm{m} \mathrm{s}^{-1}$ in the horizontal axis and in units of $-10^{-1} \mathrm{~Pa} \mathrm{~s} \mathrm{~s}^{-1}$ in the vertical axis, and vertical speed shaded in units of $-10^{-1} \mathrm{~Pa} \mathrm{~s}^{-1}$

place under the condition of strong dynamic force and abundant water vapor. The $330 \mathrm{~K}$ pseudo-equivalent potential temperature isotherm in the southern Tibetan Plateau declined from $300 \mathrm{hPa}$ on the night of March 10 to $350 \mathrm{hPa}$ in the early morning of March 12 . Meanwhile, the low-layer pseudo-equivalent potential temperature in the central Tibetan Plateau increased by $5 \mathrm{~K}$, while in the southern Plateau near Nyalam it decreased by $10 \mathrm{~K}$, due to energy gradually being released after the severe snowfall. Therefore, the atmospheric stratification stability weakened in the central Tibetan Plateau but strengthened around Nyalam.

\subsection{Mechanism of severe snowfall on southern Tibetan Plateau}

Severe snowfall took place in the southern Tibetan Plateau where the maximum snow water equivalent and depth were recorded at Nyalam, and a clear narrow snow belt came into being from eastern to southern Tibetan Plateau on March 11 (Fig. 1b). On one hand, orographic forces warm and humid airflow uplift movement along the south slope of Himalayas, which is favorable to trigger precipitation in the south slope. On the other hand, convergence of warm and humid airflow uplifted by Himalayas and cold airflow over the bulk of the Tibetan Plateau is able to strengthen precipitation. In order to investigate the significance of the above two mechanisms in this severe snowfall on southern Plateau, we analyzed the 
profiles of the conventional meteorological elements i.e. air temperature, specific humidity and 3-D wind on March 11 along line P1P2 from India to central Plateau and line P4P3 from north to south Tibet, as shown in Fig. 9.

The location of lines P1P2 and P4P3 is showed in Fig. 9a, which are chosen according to synoptic situation at $500 \mathrm{hPa}$. The profile of the conventional meteorological elements along line P1P2 is used to illustrate the role of orographic uplift, and the profile along line P4P3 is used to check the role of cold and warm humid airflow convergence. It is clear that the warm and humid airflow on the windward slope is strongly uplifted by the Himalayan terrain to a height of $300 \mathrm{hPa}$ at 08:00 BST on March 11 (Fig. 9b), which is conducive to the occurrence of heavy precipitation
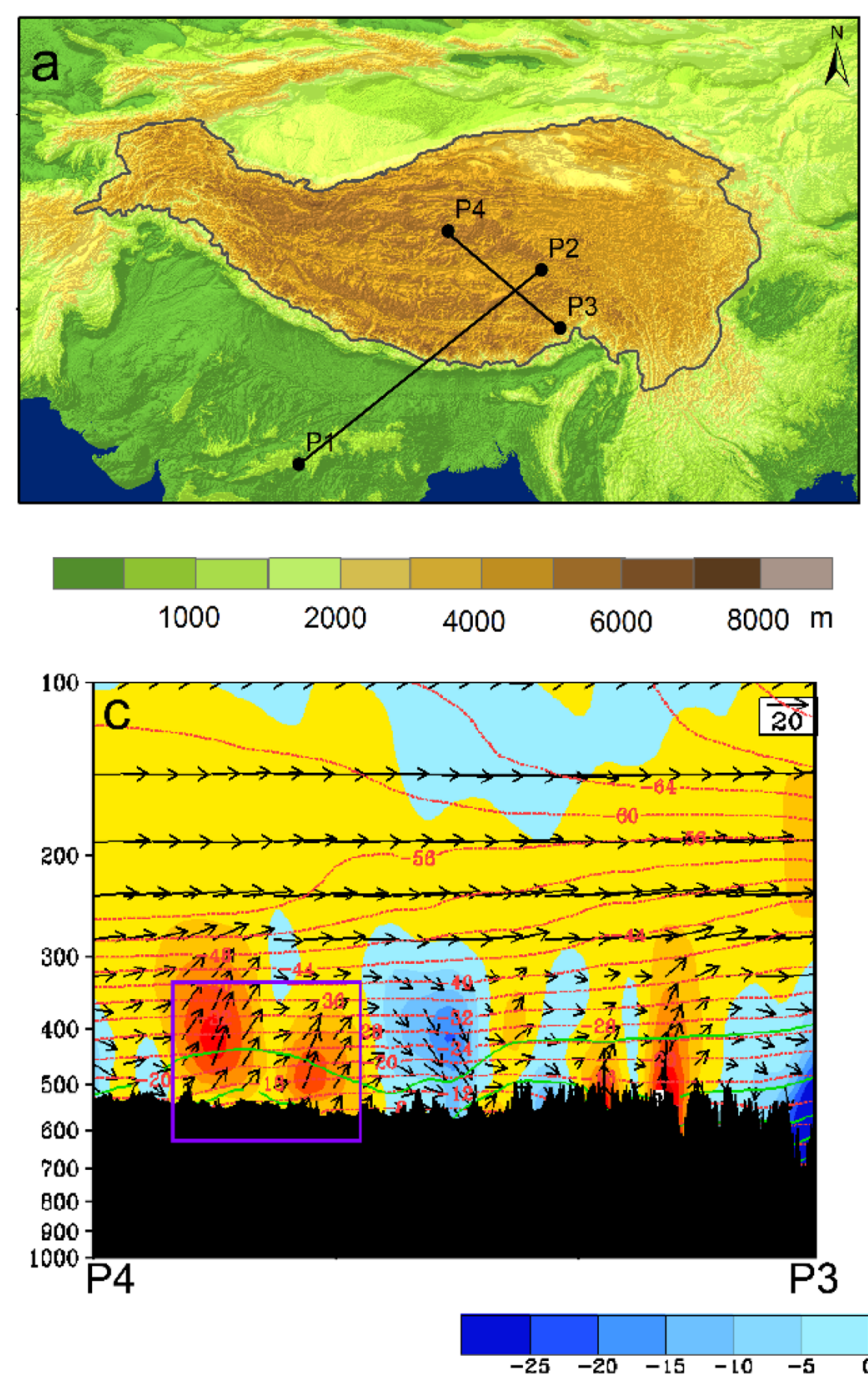

Fig. 9 Topography of the Tibetan Plateau and the surrounding region (a), same as Fig. 1a, and points P1-P4 are used in profile analysis of the conventional meteorological elements. Profile analysis along line P1P2 at 08:00 BST (b), along line P4P3 at 08:00 BST (c) and 20:00 BST (d) on March 11. Air temperature in red dotted isoline at $4{ }^{\circ} \mathrm{C}$ in the windward slope. With the horizontal current in the upper troposphere, the warm and humid airflow successfully crossed the Himalayas, and produced strong downward movement on the leeward slope. The strong downhill airflow was blocked and uplifted by the inner mountain range of the Tibetan Plateau, or merged with the weak southwest airflow to generate the southwest wind speed convergence and strong ascending movement (Fig. 9b). Simultaneously, northwest wind speed convergence occurred in the central Plateau, resulting in strong upward movement (Fig. 9c). All these are conducive to the initialization of heavy precipitation in the southern Plateau.

The northwest wind speed convergence and ascending movement continued in the central and southern Plateau. At
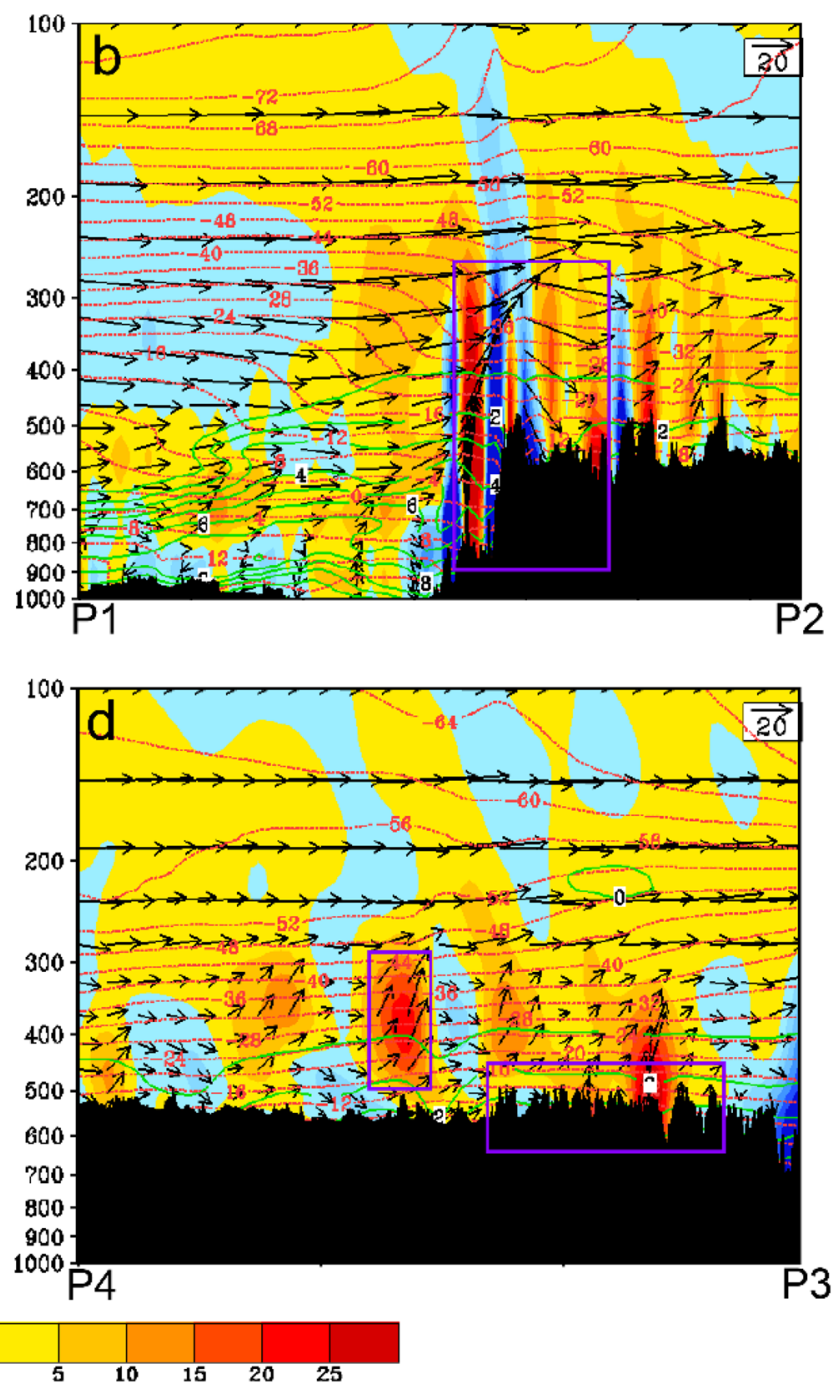

interval, specific humidity in green solid isoline at $1 \mathrm{~g} \mathrm{~kg}^{-1}$ interval, wind vectors as arrows in units of $\mathrm{m} \mathrm{s}^{-1}$ in the horizontal axis and in units of $-10^{-1} \mathrm{~Pa} \mathrm{~s}^{-1}$ in the vertical axis, and vertical speed in color shaded in units of $-10^{-1} \mathrm{~Pa} \mathrm{~s}^{-1}$. Black shadow is the elevation along line $\mathrm{P} 1 \mathrm{P} 2$ or $\mathrm{P} 4 \mathrm{P} 3$ 
20:00 BST on March 11, the northwest wind in the central Plateau weakly converged with southerly warm and humid airflow which crossed the southern boundary of the Tibetan Plateau from the bay of Bengal (Fig. 9d). All these are conducive to strengthening the snowfall in the southern Plateau. In a word, the strong orographic uplift of Himalayas and the downhill wind speed converged with horizontal current from inner Plateau are the most favorable dynamic mechanism for this severe snowfall on the southern Tibetan Plateau.

\section{WRF simulation}

The accuracy of snowstorms forecast depends primarily on the numerical simulation of atmospheric dynamics in the whole levels, and the meteorologist's capacity to detect the small-scale states that will contribute to snowfalls. It is pointed out that WRF coupled with the Community Land Model (CLM) is suitable for simulating snowfall over the Tibetan Plateau (Liu et al. 2019). In this study, the nonhydrostatic WRF model version 3.7.1 coupled with CLM was used to simulate this severe snow event.

The numerical experiment was configured for a single large domain, with an upper right boundary at $41^{\circ} \mathrm{N}$ and $110^{\circ} \mathrm{E}$, and a lower left boundary at $15^{\circ} \mathrm{N}$ and $65^{\circ} \mathrm{E}$, and the horizontal resolution was $25 \mathrm{~km}$. The model was configured to use CLM to describe all land-atmosphere interactions; the Lin scheme to represent microphysical processes; the Dudhia scheme to represent shortwave radiation, the RRTM scheme to describe longwave radiation; the YSU scheme to describe the planetary boundary layer; and the Kain-Fritsch cumulus parameterization scheme for clouds. The NCEP Final Analysis dataset with spatial resolution 0.25-degree and temporal resolution $6 \mathrm{~h}$ was used to provide initial and boundary conditions for the experiment. We conducted a 10-days simulation and the NCEP Final Analysis data at 08:00 BST on March 5, 2017 was chosen for initialization. The model results were output at a 6 -h interval. The first day was used for the model spin-up.

The WRF simulated dynamic and water vapor conditions at 20:00 BST on March 11 when snowfall strengthened in the central snow belt is showed in Fig. 10. The strongest configuration of low-level convergence and high-level divergence appeared in the central snow belt, with the divergence increase to $3.5 \times 10^{-4} \mathrm{~s}^{-1}$ above $300 \mathrm{hPa}$ and convergence increase to $-3.5 \times 10^{-4} \mathrm{~s}^{-1}$ around $450 \mathrm{hPa}$ (Fig. 10a). The favorable configuration of the whole layer horizontal divergence was also estimated in the eastern snow belt. Such these divergence configurations led to nearly whole layer upward motion prevailing over the central and eastern snow belt. The strongest upward motion areas were estimated in the central snow belt, which corresponded perfectly to the most favorable configuration areas of divergence. The maximum value of upward velocity was estimated around $300 \mathrm{hPa}$ and $0.9 \mathrm{~m} \mathrm{~s}^{-1}$ (Fig. 10c). Large positive vorticity was modeled in the central snow belt with several positive vorticity centers between 350 and $450 \mathrm{hPa}$, and the maximum value was estimated to be around $5 \times 10^{-4} \mathrm{~s}^{-1}$ (Fig. 10b). An apparent negative vorticity center located in the southern $400 \mathrm{hPa}$. Under the condition of horizontal (vertical) velocity above the southern (central) snow belt, negative (positive) vorticity advection dominated above the southern (central) areas, which resulted in the suppression (enhancement) of cyclonic vorticity above the southern (central) snow belt. These dynamic factors from WRF estimates were significance to the maintenance and enhancement of the snowfall in the central and eastern Tibetan Plateau (Fig. 10a-c).

Water vapor condition was favorable to the appearance of the snowfall from WRF estimates (Fig. 10d). Water vapor from the low-latitude regions was lifted by high topographic Himalayas and then successfully crossed the high mountains. Quite a lot of the water vapor was transported northward to the central Plateau, and some was transported to the eastern Plateau. The maximum value of water vapor flux was located in the central Plateau and slightly larger than $10 \mathrm{~g} \mathrm{~s}^{-1} \mathrm{hPa}^{-1} \mathrm{~cm}^{-1}$. And a clear water vapor convergence belt was located across the Tibetan Plateau. The remarkable water vapor convergence appeared in the central Plateau with rather high intensity higher than $-1 \times 10^{-6} \mathrm{~g} \mathrm{~s}^{-1} \mathrm{hPa}^{-1}$ $\mathrm{cm}^{-2}$. These provided sufficient water vapor for the heavy snowfall in the central and eastern Tibetan Plateau.

The dynamic and water vapor conditions in WRF simulation were well consistent with those in the reanalysis data. In other words, not only the WRF model but also the NCEP reanalysis data could be trusted in the diagnostic analysis of dynamic and thermodynamic effects on the occurrence, development and evolution of snow events in the high topographic Tibetan Plateau.

\section{Meteorological elements that lead to the heavy snowfall}

The initialization and strengthening of heavy snowfalls are under favorable synoptic circulation, dynamic and thermodynamic conditions. The development and evolution of this heavy snowfall process is not an exception, although the stable atmospheric stratification is not conducive to the continuation of this heavy snowfall. We combined the favorable synoptic situation, the related meteorological elements that lead to the heavy snowfall and the snowfall area covered by the event, which is showed in Fig. 11. It illustrates that the large-scale heavy snowfall developed under a favorable synoptic circulation. The large-scale snow belt appeared between the northeastern lower jet and the meridional shear line, with a specific humidity of around $2 \mathrm{~g} \mathrm{~kg}^{-1}$ and a 

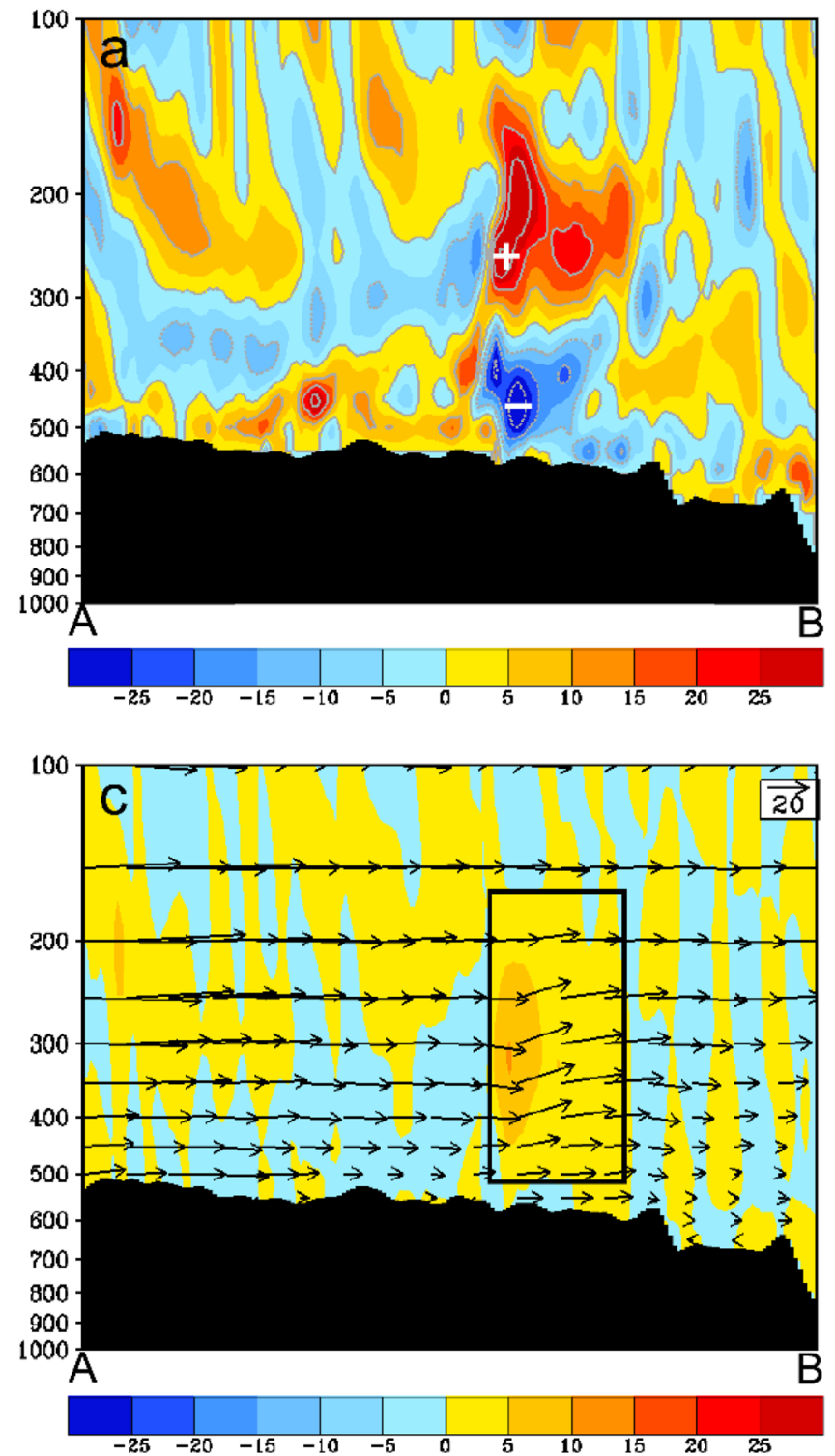

Fig. 10 WRF estimates of the profile of horizontal divergence (a) and vertical relative vorticity $(\mathbf{b})$ in color shaded and isoline at $10 \times 10^{-5}$ $\mathrm{s}^{-1}$ interval, vertical velocity in color shaded and wind vectors as arrows in units of $\mathrm{m} \mathrm{s}^{-1}$ in the horizontal axis and in units of $10^{-1}$ $\mathrm{m} \mathrm{s}^{-1}$ in the vertical axis (c) along line $\mathrm{AB}$, and the water vapor flux at $500 \mathrm{hPa}$ in units of $\mathrm{g} \mathrm{s}^{-1} \mathrm{hPa}^{-1} \mathrm{~cm}^{-1}$ and its convergence in shaded

temperature of $-16{ }^{\circ} \mathrm{C}$ at $500 \mathrm{hPa}$. The snow belt reached from the northeast to the southwest, affecting the eastern, central and southern Tibetan Plateau. The eastern and southern Plateau particularly suffered from the heavy snowfall event. The cold vortex trough extending to northwestern Plateau provided the cold air. The Southern Branch Trough in the western Tibetan Plateau was deep, providing sufficient warm water vapor through the strong southwest warm and humid airflow in front of the trough. The main body of the water vapor transport channel was located in south of the
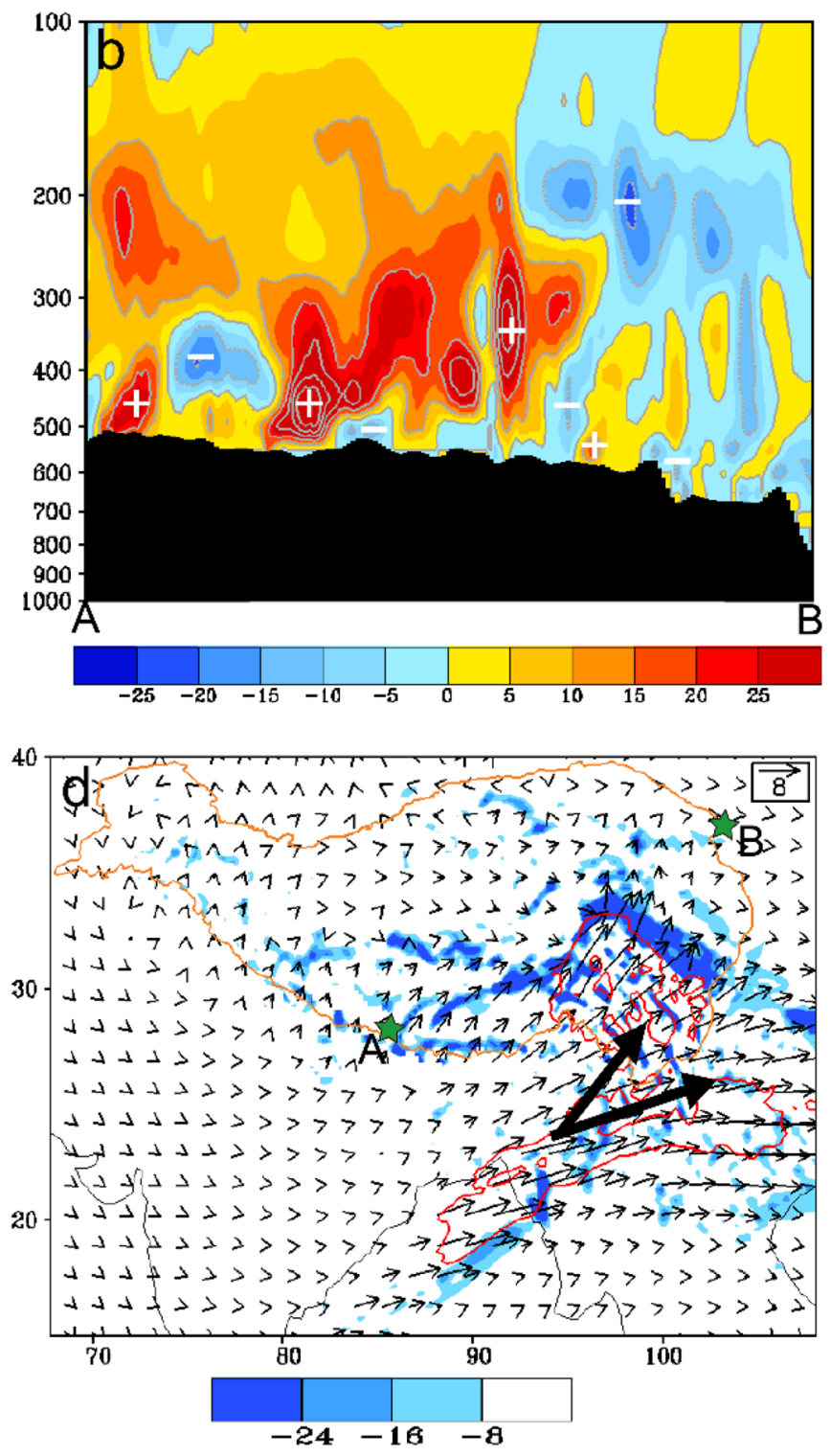

in units of $10^{-8} \mathrm{~g} \mathrm{~s}^{-1} \mathrm{hPa}^{-1} \mathrm{~cm}^{-2}$ (d) at 20:00 BST on March 11. Black shadow is the model elevation along line AB. The thick arrow shows the water vapor transport channel. The red line is water vapor flux value of $8 \mathrm{~g} \mathrm{~s}^{-1} \mathrm{hPa}^{-1} \mathrm{~cm}^{-1}$. For a description of points $\mathrm{A}$ and $\mathrm{B}$, see Fig. 1

Plateau, and the water vapor from the Bay of Bengal was transported northward and northeastward. Orographically forced snowfall has been confirmed to be important in Himalayas (Lang and Barros 2004). Due to the high-elevation Himalayas blocking transport and forcing uplift, a large proportion of the water vapor was gathered in the south slope of Himalayas, resulting in heavy snowfall. The topographic height of the southeastern Tibetan Plateau is relatively low, so the warm and humid airflow from the Bay of Bengal was easily transported to the eastern Plateau. Under the control 


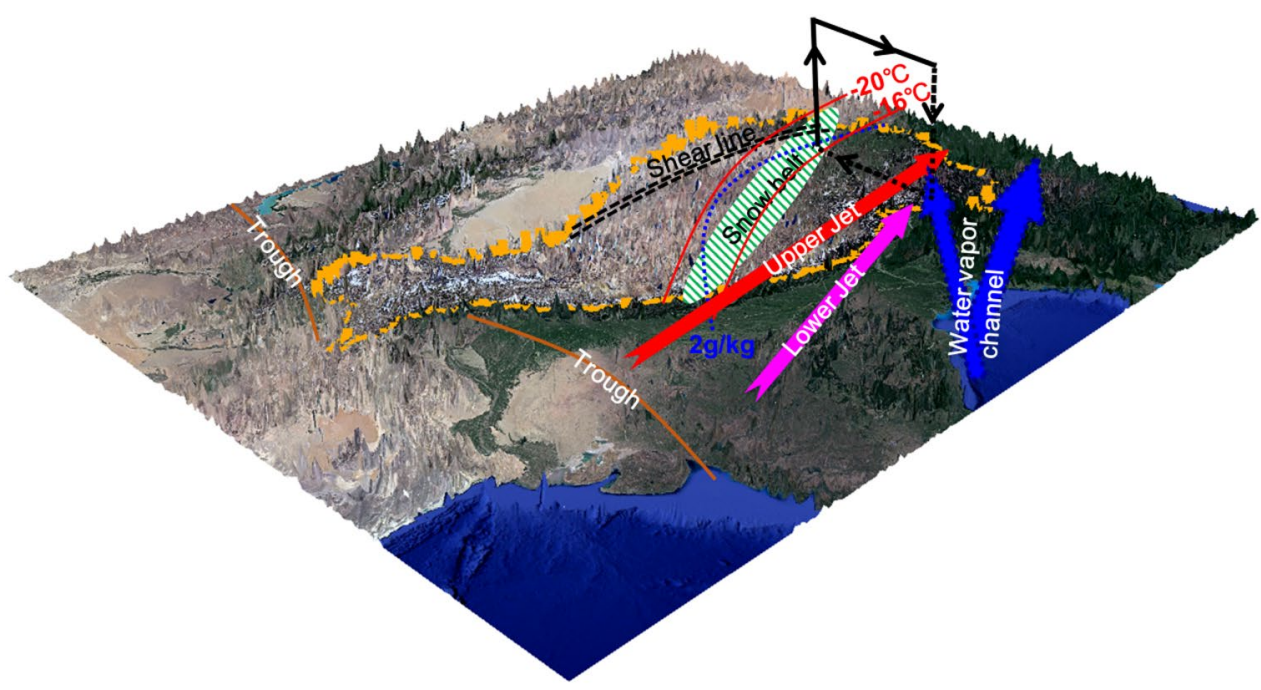

Fig. 11 Synoptic situation and favorable meteorological elements during the heavy snowfall over the Tibetan Plateau and its surroundings. The brown solid, red solid, black double dotted and blue dotted lines indicate the trough, isotherm, wind shear and specific humidity at $500 \mathrm{hPa}$ respectively. The red arrow denotes the upper jet, the rosy

of the strong ascending branch of secondary circulation on the north of the upper jet exit region, as well as rather low environmental temperature $\left(-16\right.$ to $\left.-20^{\circ} \mathrm{C}\right)$, a snowstorm was easily initiated in the eastern Tibetan Plateau.

\section{Conclusions and discussions}

It is demonstrated that excessive snowfall over the Tibetan Plateau typically appears under the conditions of the deep Indian trough, the intensified westerly jet and ascending motion, and the abundant moisture supplied by the Bay of Bengal or Indian Ocean (Zhang et al. 2004). Based on comprehensive diagnosis of various meteorological elements, this study offers a systematical analysis of a severe snowfall event through assessing the synoptic systems, upper and lower jet configurations, water vapor distribution, and dynamic and thermal conditions that lead to and persisted throughout the heavy snowfall event. The diagnostic results of the dynamic and moisture conditions from reanalysis data were well consistent with those from a WRF numerical experiment. Hereafter, the diagnostic results from reanalysis data were concluded and discussed.

Different from dynamical coupling between an upper trough and a Indian monsoon low-pressure system triggering a late summer snowstorm (Dong et al. 2018), the favorable synoptic system in our current study was characterized by the north vortex and Southern Branch Trough pattern. The cold vortex above Lake Balkhash, the Southern Branch Trough, the meridional shear line and favorable upper and red arrow denotes the lower jet, the blue arrow indicates the water vapor transport channel, and the elliptical zone is the location of the snow belt. The black arrows denote the secondary circulation near the exit region of the upper jet. The yellow line is the boundary of the Tibetan Plateau

lower jet configurations were the important trigger mechanisms of the formation and evolution of the large-scale snow belt. The structure of the jet streams has great influences on the local circulations. The remarkable horizontal gradient of wind speed near the jets is typically balanced by vertical circulations, which influences the local weather of adjacent regions (Blackmon et al. 1977; Schiemann et al. 2009). The secondary circulation of the westerly jet intensified ascending motion above the snow belt, confirming the positive effect of the westerly jet on the winter snow over the Tibetan Plateau (Bao and You 2019).

Moisture could be effectively transported to the high topographic Tibetan Plateau by circulation systems. Typically, moisture transport is closely related to synoptic-scale circulations in mid-latitudes when the moisture source is located in the north or the west (Zhang et al. 2004; You et al. 2011), and to the tropical low-pressure systems near India when the moisture is from the south (Dong et al. 2017, 2018). It has been investigated that abundant moisture can be delivered by Indian low-pressure systems via both upslope flow along the Himalayan southern slope and up-and-over transport pathways to the southwestern Tibetan Plateau (Dong et al. 2017, 2018). Statistics show that the local specific humidity before heavy snowfalls in the Tibetan Plateau increases significantly, generally above $3 \mathrm{~g} \mathrm{~kg}^{-1}$ (Zou and Cao 1991). Not only moisture channel but also transport intensity was investigated in the current work. Our study indicates that the Bay of Bengal was the main source of the water vapor transported to the Tibetan Plateau. The water vapor flux at $500 \mathrm{hPa}$ above the snow belt was as high as 
$10 \mathrm{~g} \mathrm{~s}^{-1} \mathrm{hPa}^{-1} \mathrm{~cm}^{-1}$, and its maximum convergence reached $-8.3 \times 10^{-7} \mathrm{~g} \mathrm{~s}^{-1} \mathrm{hPa}^{-1} \mathrm{~cm}^{-2}$. The convergence intensity of water vapor flux over the whole layer reached a maximum of $-4.5 \times 10^{-4} \mathrm{~g} \mathrm{~s}^{-1} \mathrm{~cm}^{-2}$. The large-scale heavy snowfall was located closely to the strong water vapor flux convergence area, with the low-layer specific humidity in the snow belt consistently greater than $2 \mathrm{~g} \mathrm{~kg}^{-1}$. Such an abundant supply of moisture is favorable for this heavy snowfall event.

Enhanced ascending motion is an essentially dynamic factor for snow increase (Wang et al. 2015, 2018). Shou and Zhu (1993) quantitatively diagnosed the vertical velocity and divergence in relation to a snowstorm in the central and eastern China. This study also quantitatively diagnoses the dynamic and thermodynamic elements during a heavy snowfall over the Tibetan Plateau. The wind field was characterized by low-level convergence and high-level divergence, upper negative and lower positive vorticity, and regionally strong ascending motion controlling two-thirds of the snow belt. The maximum vertical velocity observed was $-4 \mathrm{~Pa} \mathrm{~s}^{-1}$, three times that from Shou and Zhu (1993). The absolute values of strong convergence and strong divergence did not fall below $3 \times 10^{-4} \mathrm{~s}^{-1}$, which was close to the diagnosis results of a mountainous heavy snowfall from Gascón et al. (2015), but more than four times the absolute values from Shou and Zhu (1993), and low-level positive vorticity reached $4.8 \times 10^{-4} \mathrm{~s}^{-1}$. The upper and lower vorticity configuration, combined with the strong ascending motion, caused positive vorticity advection above the snow belt, conducive to enhancing upward motion. These describe the favorable dynamic factors that lead to the occurrence, development and continuation of the large-scale heavy snowfall over the Tibetan Plateau.

Wichansky and Harnack (2000) diagnosed the physical and dynamical variables most closely linked with a sample of snowstorms, and found the thermal advection at lower and upper tropospheric levels to be one of the best correlated variables near the conclusion of snowstorms. In our study, we also quantitatively diagnosed thermal conditions, i.e. temperature advection and atmospheric stratification. During the heavy snowfall over the Tibetan Plateau, the pseudo-equivalent potential temperature increased with height, illustrating convectively-stable stratification. This was further strengthened by warm advection in the upper layer and cold advection in the lower layer. Different from favorable temperature stratification structure of Shou and Zhu (1993), although stratification situation in this study is unfavorable for heavy snowfall, the event still occurred due to the conditions of abundant water vapor, and dynamic forced uplift over terrain.

As suggested by Fu et al. (2020), the weather systems such as the shear line and low vortex, moisture as well as atmospheric stability especially before and after a precipitation should be focused in the future researches. Such the work could be seen from our current study. Our diagnostic analysis results deepen the understanding of the occurrence and development mechanisms of severe snowfalls over the Tibetan Plateau. In discussing the causes of the heavy snowfall event, this study provides a theoretical reference and improved scientific understanding of the short-term prediction of heavy snowfall. The current study will assist in more accurate heavy snowfall forecasts for the high altitudes of the Tibetan Plateau, and will contribute to disaster prevention and mitigation in the future.

Acknowledgements This research is supported by the Strategic Priority Research Program of Chinese Academy of Sciences (XDA20060101), the Second Tibetan Plateau Scientific Expedition and Research (STEP) program (2019QZKK0103), the National Natural Science Foundation of China (91837208, 41830650, 91737205), the National Key Research and Development Program of China (2018YFC1505701) and the Chinese Academy of Sciences (QYZDJ-SSW-DQC019). The authors express thanks to NCEP for sharing atmospheric reanalysis data sets (NCEP final analysis data is available from https://rda.ucar.edu/datas ets/ds083.3/), and to staff from CMA ground stations for very hard work in meteorological observations and offering the data (CMA meteorological data is available from http://data.cma.cn/en).

Open Access This article is licensed under a Creative Commons Attribution 4.0 International License, which permits use, sharing, adaptation, distribution and reproduction in any medium or format, as long as you give appropriate credit to the original author(s) and the source, provide a link to the Creative Commons licence, and indicate if changes were made. The images or other third party material in this article are included in the article's Creative Commons licence, unless indicated otherwise in a credit line to the material. If material is not included in the article's Creative Commons licence and your intended use is not permitted by statutory regulation or exceeds the permitted use, you will need to obtain permission directly from the copyright holder. To view a copy of this licence, visit http://creativecommons.org/licenses/by/4.0/.

\section{References}

Bao Y, You Q (2019) How do westerly jet streams regulate the winter snow depth over the Tibetan Plateau? Clim Dyn 53:353-370

Blackmon ML, Wallace JM, Lau N, Mullen SL (1977) An observational study of the Northern Hemisphere wintertime circulation. J Atmos Sci 34:1040-1053

Deng H, Pepin NC, Chen Y (2017) Changes of snowfall under warming in the Tibetan Plateau. J Geophys Res Atmos 122:7323-7341

Dong W, Wei Z, Fan L (2001) Climatic character analyese of snow disasters in east Qinghai-Xizang Plateau livestock farm. Plat Meteorol 20:402-406 (in Chinese)

Dong W, Lin Y, Wright JS, Xie Y, Xu F, Xu W, Wang Y (2017) Indian monsoon low-pressure systems feed up-and-over moisture transport to the southwestern Tibetan Plateau. J Geophys Res Atmos 122:12140-12151

Dong W, Lin Y, Wright JS, Xie Y, Xu F, Yang K, Li X, Tian L, Zhao X, Cao D (2018) Connections between a late summer snowstorm over the southwestern Tibetan Plateau and a concurrent Indian monsoon low-pressure system. J Geophys Res Atmos 123:13676-13691

$\mathrm{Fu}$ Y et al (2020) Land surface processes and summer cloud-precipitation characteristics in the Tibetan Plateau and their effects on 
downstream weather: a review and perspective. Natl Sci Rev 7:500-515

Gao M, Qiu J (2011) Characteristics and distribution law of major natural disasters in Tibetan Plateau. J Arid Land Resour Environ 08:101-106 (in Chinese)

Gascón E, Sánchez JL, Charalambous D, Fernández-González S, López L, García-Ortega E, Merino A (2015) Numerical diagnosis of a heavy snowfall event in the center of the Iberian Peninsula. Atmos Res 153:250-263

Immerzeel WW, Van Beek LP, Bierkens MF (2010) Climate change will affect the Asian water towers. Science 328:1382-1385

Jiang W, Jia L, Xiao T, Luobu J, Zhou Z (2016) Climate change and spatial distribution of winter snowfall over the Tibetan Plateau during 1971-2010. J Glaciol Geocryol 38:1211-1218 (in Chinese)

Jiang X, Zhang T, Tam C, Chen J, Lau NC, Yang S, Wang Z (2019) Impacts of ENSO and IOD on snow depth over the Tibetan Plateau: roles of convections over the western North Pacific and Indian Ocean. J Geophys Res Atmos 124:11961-11975

Lan C, Zhang Y, Wang Q, Zhang L, Zhou B, Hao Z, Su F (2013) Climate change on the northern Tibetan Plateau during 1957-2009: spatial patterns and possible mechanisms. J Clim 26:85-109

Lang T, Barros AP (2004) Winter storm in the central Himalayas. J Meteorol Soc Jpn 82:829-844

Li J (2005) Why is there an early spring cooling shift downstream of the Tibetan Plateau? J Clim 18:4660-4668

Li M, Ma Y, Hu Z, Ishikawa H, Oku Y (2009) Snow distribution over the Namco lake area of the Tibetan Plateau. Hydrol Earth Syst Sci 13:2023-2030

Liang X, Qian Z, Li W (2002) Analyses on circulation patterns and water vapor fields of snow disaster weather in eastern pasture areas of Qinghai-Xizang Plateau. Plat Meteorol 21:359-367 (in Chinese)

Lin Z, Jia L, Xue G, Pubu C, Xu J (2014) Spatial-temporal distribution and general circulation of heavy snow over Tibet Plateau in 1980-2000. Plat Meteorol 33:900-906 (in Chinese)

Liu Y, Qian Z (2005) The affection of land and sea thermal difference to climate change in China. China Meteorological Press, Beijing

Liu F, Mao X, Zhang Y, Chen Q, Liu P, Zhao Z (2014) Risk analysis of snow disaster in the pastoral areas of the Qinghai-Tibet plateau. J Geogr Sci 24:411-426

Liu L, Ma Y, Menenti M, Zhang X, Ma W (2019) Evaluation of WRF modeling in relation to different land surface schemes and initial and boundary conditions: a snow event simulation over the Tibetan Plateau. J Geophys Res Atmos 124:209-226

Lü J, Ju J, Kim S, Ren J, Zhu Y (2008) Arctic Oscillation and the autumn/winter snow depth over the Tibetan Plateau. J Geophys Res Atmos 113:D14117

Mao J (2010) Interannual variability of snow depth over the Tibetan Plateau and its associated atmospheric circulation anomalies. Atmos Ocean Sci Lett 3:213-218

Qin D, Liu S, Li P (2006) Snow cover distribution, variability, and response to climate change in western China. J Clim 19:1820-1833

Qin D, Zhang J, Shan C, Song L (2015) China national assessment report on risk management and adaptation of climate extremes and disasters. Science Press, Beijing

Sato T (2001) Spatial and temporal variations of frozen ground and snow cover in the eastern part of the Tibetan Plateau. J Meteorol Soc Jpn 79:519-534

Schiemann R, Lüthi D, Schär C (2009) Seasonality and interannual variability of the westerly jet in the Tibetan Plateau region. J Clim 22:2940-2957
Shaman J, Tziperman E (2005) The effect of ENSO on Tibetan Plateau snow depth: a stationary wave teleconnection mechanism and implications for the south Asian monsoons. J Clim 18:2067-2079

Shang Z, Gibb MJ, Long R (2012) Effect of snow disasters on livestock farming in some rangeland regions of China and mitigation strategies-a review. Rangel J 34:89-101

Shou S, Zhu A (1993) Diagnostic study of a winter snowstorm event. Adv Atmos Sci 10:428-434

Skamarock W, Klemp JB, Dudhia J, Gill DO, Barker DM, Wang W, Powers JG (2008) A description of the advanced research WRF version 3, NCAR Technical Note NCAR/TN-475 + STR

Ueno K (2005) Synoptic conditions causing nonmonsoon snowfalls in the Tibetan Plateau. Geophys Res Lett 32:L01811

Wang Y, Wang J, Li S, Qin D (2014) Vulnerability of the Tibetan pastoral systems to climate and global change. Ecol Soc 19:8

Wang S, Fosu B, Gillies RR, Singh PM (2015) The deadly Himalayan snowstorm of October 2014: synoptic conditions and associated trends, [in "Explaining extremes of 2014 from a climate perspective"]. Bull Am Meteorol Soc 96:S89-S94

Wang C, Yang K, Li Y, Wu D, Bo Y (2017) Impacts of spatiotemporal anomalies of Tibetan Plateau snow cover on summer precipitation in eastern China. J Clim 30:885-903

Wang Z, Wu R, Huang G (2018) Low-frequency snow changes over the Tibetan Plateau. Int J Clim 38:949-963

Wei Y, Wang S, Fang Y, Nawaz Z (2017) Integrated assessment on the vulnerability of animal husbandry to snow disasters under climate change in the Qinghai-Tibetan Plateau. Glob Planet Change 157:139-152

Wichansky PS, Harnack RP (2000) A diagnosis of tropospheric effects upon surface precipitation amount for a sample of east coast snowstorms. Weather Forecast 15:339-348

Xiao Z, Duan A (2016) Impacts of Tibetan Plateau snow cover on the interannual variability of the east Asian summer monsoon. J Clim 29:8495-8514

You Q, Kang S, Ren G, Fraedrich K, Pepin N, Yan Y, Ma L (2011) Observed changes in snow depth and number of snow days in the eastern and central Tibetan Plateau. Clim Res 46:171-183

Yuan C, Tozuka T, Miyasaka T, Yamagata T (2009) Respective influences of IOD and ENSO on the Tibetan snow cover in early winter. Clim Dyn 33:509-520

Yuan C, Tozuka T, Yamagata T (2012) IOD influence on the early winter Tibetan Plateau snow cover: diagnostic analyses and an AGCM simulation. Clim Dyn 39:1643-1660

Zhang Y, Li T, Wang B (2004) Decadal change of the spring snow depth over the Tibetan Plateau: the associated circulation and influence on the east Asian summer monsoon. J Clim 17:2780-2793

Zhu Y, Liu H, Ding Y, Zhang F, Li W (2015) Interdecadal variation of spring snow depth over the Tibetan Plateau and its influence on summer rainfall over east China in the recent 30 years. Int $\mathrm{J}$ Clim 35:3654-3660

Zou J, Cao C (1989) Climatological analysis of snowfall over the Qinghai-Xizang Plateau. Chin J Atmos Sci 13:400-409 (in Chinese)

Zou J, Cao C (1991) Some factors of impacts on snowfall over QinghaiXizang Plateau. Adv Water Sci 2:42-49 (in Chinese)

Publisher's Note Springer Nature remains neutral with regard to jurisdictional claims in published maps and institutional affiliations. 